\title{
EVIDENCIA ARQUEOLÓGICA DE NAUFRAGIOS EN ZONAS COSTERAS: EL CASO DEL PARQUE NACIONAL MONTE LEÓN (PROVINCIA DE SANTA CRUZ)
}

\author{
MÓNICA GROSSO ${ }^{a}$, DOLORES ELKIN $^{b}$, CRISTIAN MURRAYc $\&$ MARÍA ÁGUEDA CASTRO $^{d}$
}

\begin{abstract}
RESUMEN
En este trabajo se presentan las investigaciones desarrolladas en el área costera del Parque Nacional Monte León (provincia de Santa Cruz, Argentina) en relación a la evidencia arqueológica de naufragios de tiempos históricos. El estudio incluye el análisis de antecedentes relevantes para el área de estudio y el planteo de la metodología de trabajo en función de los objetivos propuestos y de las características ambientales del área. Dicha metodología se basó en la realización de prospecciones sistemáticas en sectores intermareales y supramareales. Se presenta un análisis de los principales indicadores utilizados para la interpretación de restos de naufragios desarticulados y dispersos, incluyendo caracterizaciones metalúrgicas y determinaciones taxonómicas de maderas. Se consideran también los procesos de formación intervinientes en este tipo de contextos ambientales, como así también el estado de preservación y los riesgos de alteración a los que están sujetos estos materiales. De este modo fue posible realizar una aproximación a la tipología, características y cronología de las embarcaciones representadas.
\end{abstract}

PALABRAS CLAVE: arqueología de naufragios, intermareal, Parque Nacional Monte León, Patagonia, Argentina

ARCHAEOLOGICAL SHIPWRECK EVIDENCE IN COASTAL AREAS: THE CASE OF MONTE LEÓN NATIONAL PARK (SANTA CRUZ PROVINCE)

\section{ABSTRACT}

This paper presents the results of the investigations conducted in the coastal area of the Parque Nacional Monte León (Monte León National Park), Santa Cruz Province, Argentina, in relation to the archaeological evidence of historic shipwrecks. The study includes the analysis of the relevant background

a Instituto Nacional de Antropología y Pensamiento Latinoamericano (INAPL). 3 de Febrero 1378 (C1426BJN) Ciudad de Buenos Aires. monigrosso@hotmail.com

b CONICET-INAPL. lolielkin@hotmail.com

c INAPL. cristianmurray@yahoo.com.ar

d Laboratorio de Anatomía Vegetal, Facultad de Ciencias Exactas y Naturales, Universidad de Buenos Aires. Ciudad Universitaria. macastro002@gmail.com 
information for the study area and the proposal of the methodology to be applied on the basis of the research goals and the general environmental characteristics of the area. Such methodology was based on systematic surveys on intertidal and supratidal sectors. An analysis of the main indicators used in the interpretation of disassembled and scattered shipwreck remains is presented, including metallurgic characterizations and taxonomic wood identifications. The site formation processes which play a role in these types of environmental contexts are also considered, as well as the state of preservation and risk of alteration of these materials. In this manner, it was possible to infer the general typology, characteristics and chronology of the vessels which are represented.

KEYWORDS: shipwreck archaeology, intertidal zone, Monte León National Park, Argentina, Patagonia

\section{INTRODUCCIÓN Y OBJETIVOS}

El Parque Nacional Monte León (PNML), creado en 2004, es el primer parque nacional con costa sobre el litoral marítimo argentino. Está localizado en el sureste de la provincia de Santa Cruz, entre $50^{\circ} 12^{\prime}$ y $50^{\circ} 28^{\prime}$ de latitud S y $68^{\circ}$ $43^{\prime}$ y $69^{\circ} 11^{\prime}$ de longitud $\mathrm{O}$, y cubre un área de más de 60.000 hectáreas, con aproximadamente $40 \mathrm{~km}$ de línea costera (Fig. 1).

En el marco de los estudios de base previstos para la implementación de un plan de manejo del Parque, se incluyó el estudio de evidencia arqueológica vinculada con la navegación en tiempos históricos ${ }^{1}$. Esto se debió a que no existían estudios previos sobre esta temática pese a conocerse la existencia de un considerable número de restos de naufragios dispersos a lo largo de sus costas. Las únicas intervenciones que se habían realizado hasta aquel momento estaban dirigidas a la búsqueda de restos de una embarcación en particular (tema que se retomará más adelante), o bien consistían en recolecciones asistemáticas por parte de habitantes de las localidades cercanas.

Cabe señalar que las costas de la provincia de Santa Cruz, así como otras zonas del litoral Patagónico, han sido de interés para las potencias marítimas europeas a partir del siglo XVI, en el contexto de los viajes de exploración, colonización y explotación comercial de nuevas regiones. A lo largo del tiempo, embarcaciones de variados orígenes estuvieron involucradas en diversas actividades náuticas en el área de estudio. Estas pueden relacionarse históricamente con tres

1 Esta investigación fue encomendada al Programa de Arqueología Subacuática del Instituto Nacional de Antropología y Pensamiento Latinoamericano por la aspectos principales:

- Proximidad a la única ruta marítima interoceánica entre el Atlántico y el Pacífico existente hasta 1914 (año de la apertura del Canal de Panamá).

- Cercanía a algunos de los escasos puertos naturales de la región (Puerto Santa Cruz, distante $45 \mathrm{~km}$, y Puerto San Julián, distante $175 \mathrm{~km}$, aproximadamente).

- Actividades extractivas y productivas (loberías, guano y, posteriormente, ganado ovino); transporte de personas y bienes.

Uno de los eventos históricos más significativos para esta región está vinculado con la expedición, originalmente al mando de Fernando de Magallanes, que logró realizar la primera circunnavegación del mundo. En 1520 una de sus embarcaciones, la Santiago, naufragó en un sector de la costa que, de acuerdo a las fuentes documentales, podría estar localizado dentro de los límites del PNML.

En base a todo lo señalado previamente, los objetivos de dicho estudio consistieron en (Elkin et al. 2007):

1) Obtener información de base sobre las características y localización del registro arqueológico vinculado a la navegación en tiempos históricos existente en el área.

2) Evaluar posibles asociaciones entre dicho registro y los eventos de naufragio ocurridos en la zona para los cuales se dispone

Administración de Parques Nacionales en el marco del Proyecto Conservación de la Biodiversidad GEF TF 028372-AR. 
Fig. 1. Ubicación del Parque Nacional Monte León en la costa de la provincia de Santa Cruz, Argentina.

de información histórica.

3) Caracterizar su estado de preservación y los riesgos de alteración.

Para lograr los objetivos planteados, en una primera etapa se analizaron las condiciones ambientales, la geomorfología y la dinámica costera del área, tanto para evaluar las expectativas arqueológicas como en función del desarrollo del trabajo de campo. Asimismo, se llevó a cabo un análisis de fuentes históricas relativas a las actividades marítimas y los naufragios documentados para la región, en particular vinculadas a la expedición de Magallanes. Luego se examinaron los antecedentes de estudios y observaciones de materiales arqueológicos de origen náutico efectuados en el área. Esto incluyó un relevamiento sistemático de este tipo de materiales que habían sido recolectados previamente en la zona de estudio por pobladores locales y la recopilación de información sobre su procedencia en base a fuentes orales. Para el relevamiento de materiales en el campo se planificó una metodología diseñada en función de lo expuesto y considerando las características predominantes de las grandes extensiones de las zonas intermareales patagónicas.

En este trabajo se presentan los resultados obtenidos en el estudio referido y se analizan, además, aspectos vinculados a la arqueología de restos náufragos costeros y los procesos de formación en ambientes intermareales. Asimismo, se detalla la metodología implementada para la interpretación de las embarcaciones representadas.

\section{ARQUEOLOGÍA DE RESTOS NÁUFRAGOS COSTEROS}

Los restos de naufragios depositados 
de construcción, tratados de construcción naval y reglas de clasificación de buques, los cuales permiten disponer de información comparativa para determinar la antigüedad aproximada del barco, su tonelaje y si existen correspondencias con algún naufragio particular históricamente documentado (Russell, 2005). A principios del siglo XIX comienzan a surgir, primero en Gran Bretaña y luego en otros países, las Sociedades de Clasificación, que inspeccionaban y calificaban periódicamente a las embarcaciones en relación a determinados estándares constructivos con el fin de proveer a los armadores y aseguradores de información confiable sobre la condición en la que se encontraban (Crothers, 1997; Desmond, [1919] 1984). Las reglas que establecían estas sociedades y las listas de las embarcaciones clasificadas eran publicadas periódicamente, por lo cual actualmente se dispone de abundante información acerca de dimensiones, proporciones, materiales y características de los distintos componentes de una embarcación en función de su tamaño (entre las reglas más utilizadas pueden mencionarse las de la británica Lloyd's Register, la americana American Bureau of Shipping y la francesa Bureau Veritas).

Cabe hacer algunas consideraciones acerca de los procesos de formación del registro arqueológico en ambientes marinos, los cuales presentan rasgos particulares respecto a otro tipo de sitios (Muckelroy, 1978; Ward et al. 1999). Esto se debe fundamentalmente al hecho de que el naufragio de una embarcación es un proceso que ocurre en un medio altamente dinámico como es el mar. Dependiendo de diversas variables, la embarcación o partes de ella pueden quedar depositadas en las costas (Delgado, 1997; Russell, 2005; Grosso et al. 2013). Si bien es habitual ver restos de naufragios dispersos en grandes extensiones en ambientes costeros, desafortunadamente hasta el presente se han publicado escasos trabajos en los que se consideran estos procesos de formación. Entre ellos se destaca el estudio comprehensivo llevado a cabo por Russell (1995, 2004).

En función de las distintas circunstancias que pudieron haber originado la pérdida de una embarcación y las condiciones del medio ambiente en que ello tuvo lugar, el proceso de naufragio pudo ocurrir en forma rápida o bien a lo largo de varios días (Gibbs, 2006). Por ejemplo, no es lo mismo que una embarcación haya naufragado a causa de una explosión, a que se haya hundido sin mayores daños de su casco. Por su parte, factores ambientales como la intensidad y dirección del viento, oleaje y corrientes, así como el tipo de fondo, también habrán jugado un rol fundamental.

A partir de allí, y en función de la subsiguiente interacción de los materiales con los diferentes factores naturales y culturales, se irá perfilando el nivel de integridad de la embarcación como así también el grado de dispersión de los restos. Las características hidrodinámicas, topográficas y el tipo de fondo incidirán en las posibilidades y condiciones de su enterramiento. Los restos depositados en la costa podrán ser eventualmente desplazados o arrastrados nuevamente hacia el mar. En términos generales, en ambientes marinos, las condiciones más propicias para la preservación de los materiales las ofrecen los sustratos blandos, que favorecen su enterramiento. En particular, los contextos más favorables son los depósitos estables formados por las fracciones granulométricas más finas (arcillas, limos y arenas finas). De este modo, quedan resguardados de la acción físico-química de los agentes ambientales bióticos y abióticos, y se reducen las posibilidades de dispersión (ver, por ejemplo, Pearson, 1987; Gregory, 1998; Ward et al. 1999; Grosso et al. 2013). Asimismo, en estas condiciones se ven reducidas las posibles actividades de recuperación antrópica.

En caso de que los restos de un naufragio no se cubran rápidamente con sedimento, podrán perder parte de sus elementos componentes al ser removidos o arrastrados por la acción de las olas y corrientes. De este modo, algunos de estos restos -particularmente la madera, debido a su flotabilidad- podrán dispersarse y, eventualmente, ser depositados en las costas en función de la dirección de los vientos, las corrientes de mareas, la deriva litoral y los rasgos topográficos.

En las ocasiones en que se combinan eventos de tormenta con mareas de sicigias, los restos depositados en playas podrán ser desplazados más allá de la línea de resaca (alejándolos del mar). Esto les brindará cierta estabilidad en cuanto a su localización, ya que quedarán fuera del alcance de las aguas hasta que eventualmente suceda otro evento del mismo tipo. 


\section{CARACTERÍSTICAS AMBIENTALES DEL PNML}

La morfología costera del PNML está dominada por la presencia de acantilados de altura mediana a elevada atravesados por cañadones. Predominan las playas longilíneas de rodados, las cuales son de pequeño desarrollo. Muchas de estas playas quedan cubiertas por el agua con las mareas altas. Al pie de los acantilados mejor desarrollados se localizan planicies de abrasión (también llamadas restingas) labradas en la formación Monte León, algunas de las cuales llegan a alcanzar una gran extensión. En ellas se observan frecuentemente acanaladuras de profundidad variable perpendiculares a la línea de costa, ocasionadas por el desplazamiento de los rodados debido al movimiento de olas y la acción de las mareas (Codignotto \& Ercolano, 2006).

El $95 \%$ de la costa está dominada por acantilados activos, ya que los procesos erosivos marinos dan lugar al retroceso costero. La dinámica costera que caracteriza la zona produce modificaciones morfológicas de tipo rápido en función del rango de mareas, el impacto de las olas, la frecuencia e intensidad de las tormentas y la deriva litoral (Codignotto \& Ercolano, 2006).

En esta área se registra un régimen de mareas semidiurno (dos pleamares y dos bajamares diarias) con rango macromareal, que alcanza una amplitud de alrededor de $12 \mathrm{~m}$ en las mareas de sicigia. Esto ocasiona que durante las bajas mareas se expongan amplias extensiones de playas o de planicies de abrasión, que llegan a alcanzar los $1.500 \mathrm{~m}$ de ancho. En la costa del PNML la dirección de la deriva litoral es hacia el sector sur y constituye un factor importante de transporte de sedimentos y erosión (Codignotto \& Ercolano, 2006).

\section{ANALISIS DE ANTECEDENTES RELEVANTES PARA EL ÁREA DE ESTUDIO}

\section{Actividades marítimas en tiempos históricos}

En 1519 el navegante Fernando de

2 La nao era un tipo de embarcación de origen portugués que se utilizó con frecuencia en los viajes de exploración emprendidos desde la Península Ibérica durante los siglos XV y XVI. Podía transportar la carga y el armamento
Magallanes partió de España al mando de cinco naves en búsqueda de un pasaje que conectara los océanos Atlántico y Pacífico por el extremo sur de América. Al año siguiente, en las costas de la actual provincia de Santa Cruz se produjo la pérdida de la menor de las embarcaciones, la Santiago. Las fuentes mencionan que el barco se perdió cuando fue empujado por un temporal hacia la costa, donde encalló. Esto sucedió cuando estaba realizando exploraciones de avanzada en la zona del río Santa Cruz, mientras que el resto de las embarcaciones de la flota se encontraban aguardando noticias en Puerto San Julián, localizado 110 km hacia el norte. Luego del naufragio, parte de la tripulación se abocó, durante dos meses, a recuperar todo aquello considerado de utilidad (Albo, [1522] 1946; Pigafetta, [1522?] 1954; Elcano, [1522] 2003; Mafra, [1522?] 2003; Transilvano, [1523] 1946).

Las crónicas refieren a la Santiago como una nao ${ }^{2}$. De acuerdo a las fuentes, se trataba de una embarcación de 75 toneladas aparejada con palos trinquete, mayor y mesana. Contaba con dos anclas, ocho remos, dos bombas y un bote. Como armamento llevaba dos bombardas, dos falconetes, ocho versos y armas menores (AGN, Sección Patronato 34, R.10, nd; Fernández de Navarrete, [1837] 1946).

Sobre la base del análisis comparativo de las diversas fuentes consultadas, fue posible evaluar distintas alternativas respecto al lugar donde ocurrió el naufragio de la Santiago. En relación al área de estudio, dos zonas potenciales fueron identificadas: una de ellas en el extremo norte del Parque y la otra en la zona centro-sur. Asimismo, se puede inferir que la embarcación se perdió en las proximidades de la costa, en la zona intermareal. Considerando que la tripulación realizó rescates, probablemente sólo habrían quedado elementos vinculados a la estructura del barco u otros que fueran difíciles de recuperar, o bien que no fueran considerados valiosos. Deben también tomarse en cuenta aquellos factores de indole natural $y$ cultural que pudieron haber afectado los materiales sobrevivientes a lo largo de casi cinco siglos. Esto permite concluir que, de subsistir restos de

necesarios para viajes prolongados sin sacrificar resistencia y velocidad. Era menos ágil que la carabela, pero más grande y con mayor manga y altura en la bodega (Smith, 1993). 
Tabla 1. Naufragios documentados para la región de acuerdo con Galdeano (2006).

\begin{tabular}{|c|c|c|c|c|c|c|}
\hline \multirow{2}{*}{$\begin{array}{l}\text { Nombre del } \\
\text { barco }\end{array}$} & & \multirow{2}{*}{ Año y lugar de naufragio } & \multicolumn{3}{|c|}{ Características del barco } & \multirow{2}{*}{ Bandera } \\
\hline & & & Tipo & Casco & $\operatorname{Tn}$ & \\
\hline Santiago & 1520 & 3 leguas al sur del río Santa Cruz & $\mathrm{NaO}$ & Madera & 90 & España \\
\hline $\begin{array}{l}\text { Pasquale } \\
\text { Quartino }\end{array}$ & 1874 & $\begin{array}{l}\text { Salió desde Puerto Santa Cruz y no } \\
\text { se volvió a saber de él }\end{array}$ & Cúter & - & - & Argentina \\
\hline Mary E. Parker & 1874 & En cercanías de Puerto Santa Cruz & $\begin{array}{l}\text { Barca de } 3 \\
\text { palos }\end{array}$ & Madera & - & $\begin{array}{l}\text { Estados } \\
\text { Unidos }\end{array}$ \\
\hline Cuba & 1878 & $\begin{array}{l}12 \text { millas al SO de la boca del río } \\
\text { Santa Cruz }\end{array}$ & Barca & - & - & Noruega \\
\hline Bouchard & 1878 & $\begin{array}{l}\text { Cerca de la desembocadura del Río } \\
\text { Chico }\end{array}$ & Lugre & Madera & - & Argentina \\
\hline Los Estados & 1886 & Cerca de la ría Santa Cruz & Cúter & Madera & $\begin{array}{c}18 \\
\text { (desplazamiento) }\end{array}$ & Argentina \\
\hline Victoria & 1889 & En la entrada de Puerto Santa Cruz & $\begin{array}{l}\text { Goleta de } 2 \\
\text { palos }\end{array}$ & - & 25 (registro) & Chile \\
\hline Sara & 1922 & Bahía Santa Cruz & $\begin{array}{l}\text { Goleta de } 3 \\
\text { palos }\end{array}$ & Madera & 416 (registro) & Chile \\
\hline Antartic & - & $\begin{array}{l}\text { A } 3 \text { millas de Punta Entrada, frente } \\
\text { a Puerto Santa Cruz }\end{array}$ & Goleta & Madera & - & - \\
\hline
\end{tabular}

la Santiago, ellos podrían consistir en materiales pesados tales como el lastre, anclas y/o algún componente estructural de la embarcación. En cualquier caso, excepto por las anclas, se trataría de materiales con baja visibilidad arqueológica.

Luego del viaje de Magallanes y hasta inicios del siglo XX, se registran diversas expediciones que ingresaron al río Santa Cruz, pasaron frente a su desembocadura o pudieron haberlo hecho durante su navegación hacia el sur (Lenzi, 1980). Varios de estos viajes tenían entre sus objetivos actividades de exploración, militares y científicas. La navegación también estuvo estrechamente vinculada con el transporte de personas y mercaderías, como así también con la explotación de recursos naturales. Respecto a esto último, cabe señalar que en la isla Monte León, en el actual PNML, se llevó a cabo desde mediados del siglo XIX la extracción de guano de cormoranes para ser utilizado como fertilizante. Hacia mediados del siglo XX éste llegó a ser el yacimiento guanero más importante del país. Durante la primera mitad del siglo XX también se registró una intensa actividad de caza de lobos marinos de un pelo (Otaria flavescens), cuyas poblaciones dentro de los límites del actual Parque formaban colonias muy numerosas. De ellos se obtenían la grasa, la piel y la carne. Asimismo, desde las últimas décadas del siglo XIX tomó impulso en la región la industria ganadera ovina y se impuso como actividad productiva predominante (Moreno, 1947; Godoy, 1963; Lenzi, 1980; Punta, 1996).

Como resultado de la actividad náutica desarrollada durante todo este tiempo se produjeron varios naufragios. Para algunos de ellos se dispone de información proveniente de distintas fuentes bibliográficas (principalmente compiladas por Galdeano, 2006) y archivos oficiales, como los de la Prefectura Naval Argentina y la Armada Argentina. La consulta de estas fuentes permitió obtener información de cerca de una decena de naufragios ocurridos hasta mediados del siglo XX (Tabla 1), en su mayoría localizados en las cercanías de la desembocadura del río Santa Cruz, la cual se encuentra a $25 \mathrm{~km}$ al norte del PNML. Tal como puede verse en la Tabla 1, predominan los registros de naufragios ocurridos a partir de fines del siglo XIX. Cabe señalar que este limite temporal puede responder a un sesgo vinculado con la aparición de registros de índole oficial una vez que se establecieron poblaciones permanentes en la provincia de Santa Cruz a partir de esa misma época.

Intervenciones previas en el área

Entre los años 2000 y 2002, previamente a 
la creación del PNML, se llevaron a cabo diversos relevamientos en la zona de estudio. Uno de ellos fue el realizado en el marco de un proyecto desarrollado en forma conjunta por museos de Argentina y Estados Unidos, con el objetivo de localizar los restos de la nao Santiago. Durante estas prospecciones se hallaron y registraron varios restos de naufragios en la franja costera del PNML. Se llevaron a cabo diversos análisis y caracterizaciones de los materiales, los cuales llevaron a la conclusión de que algunos de ellos podrían haber pertenecido a la Santiago (ver, por ejemplo, Aldazábal, 2000). No obstante, el análisis efectuado de esta y otras fuentes suministradas por la Administración de Parques Nacionales a los fines de esta investigación, revela que dicha evidencia no es concluyente.

Otra instancia de trabajo fue llevada a cabo por los arqueólogos A. Argüeso y A. Cazenave de la Roche, con el objetivo de inspeccionar ciertos items que algunos de los pobladores locales atribuían a la Santiago. En base a sus rasgos tecnotipológicos, los materiales fueron asignados al siglo XIX en adelante, con la excepción de una sola pieza (una vigota) que podría haber pertenecido a cualquier período de la navegación a vela a partir del siglo XVI (Argüeso, 2001); sobre esta pieza se volverá más adelante.

En las últimas décadas, una serie de relevamientos costeros asistemáticos fueron llevados a cabo por pobladores de las localidades cercanas al actual PNML. Las actividades más relevantes fueron realizadas por personal del Museo Carlos Borgialli de la ciudad de Puerto Santa Cruz, recolectando una cantidad significativa de materiales provenientes de restos náuticos a lo largo de varios años (Hernández, com. pers.). Materiales recolectados por otros pobladores se localizan en la vecina ciudad de Comandante Luis Piedra Buena.

\section{METODOLOGÍA}

Para ajustar la planificación del trabajo en el terreno se analizaron imágenes satelitales y se realizó un sobrevuelo de la costa del PNML. Esto también permitió tomar medidas de seguridad durante el desarrollo del trabajo en función del nivel de las mareas y la topografía del terreno, ya que en muchos sectores del Parque las aguas alcanzan el pie de los acantilados durante las mareas altas.

En función de lo precedente, como así también del tiempo y los recursos disponibles, se diseñó la metodología de relevamiento en el campo. Se planificó la realización de una prospección sistemática de la costa mediante un relevamiento diferencial, acorde con los criterios que se indican a continuación.

En primer lugar, se planteó realizar un relevamiento extensivo cubriendo los $40 \mathrm{~km}$ del frente costero del Parque mediante transectas paralelas en las zonas supramareal $e$ intermareal superior, dado que era esperable que en estos sectores se depositaran la mayor cantidad de elementos transportados por las mareas.

Por otra parte se previó la realización de un relevamiento intensivo en los sectores para los cuales:

a) existieran antecedentes de hallazgos previos,

b) se identificara mayor potencial arqueológico en base a fuentes históricas, o bien,

c) se localizaran evidencias materiales durante las prospecciones en curso y se considerara conveniente relevar en mayor detalle dicho sector.

En estos sectores la prospección se ampliaría también hacia la zona intermareal media e inferior, realizando el relevamiento durante las mareas bajas. Como ya se indicó, en esta región la zona intermareal puede alcanzar una gran extensión en función de la elevada amplitud de marea.

Debido a que la jurisdicción del PNML llega hasta el límite inferior del intermareal, para este trabajo no se incluyeron prospecciones submareales. No obstante, en función de los resultados que se obtuviesen en las investigaciones, no se descartaba la posibilidad de realizarlas en un futuro.

En términos generales las transectas -separadas $10 \mathrm{~m}$ entre sí- fueron realizadas por un equipo compuesto por entre 4 y 5 personas (Fig. 2). En sectores con visibilidad reducida (por ejemplo, formaciones rocosas en zonas 


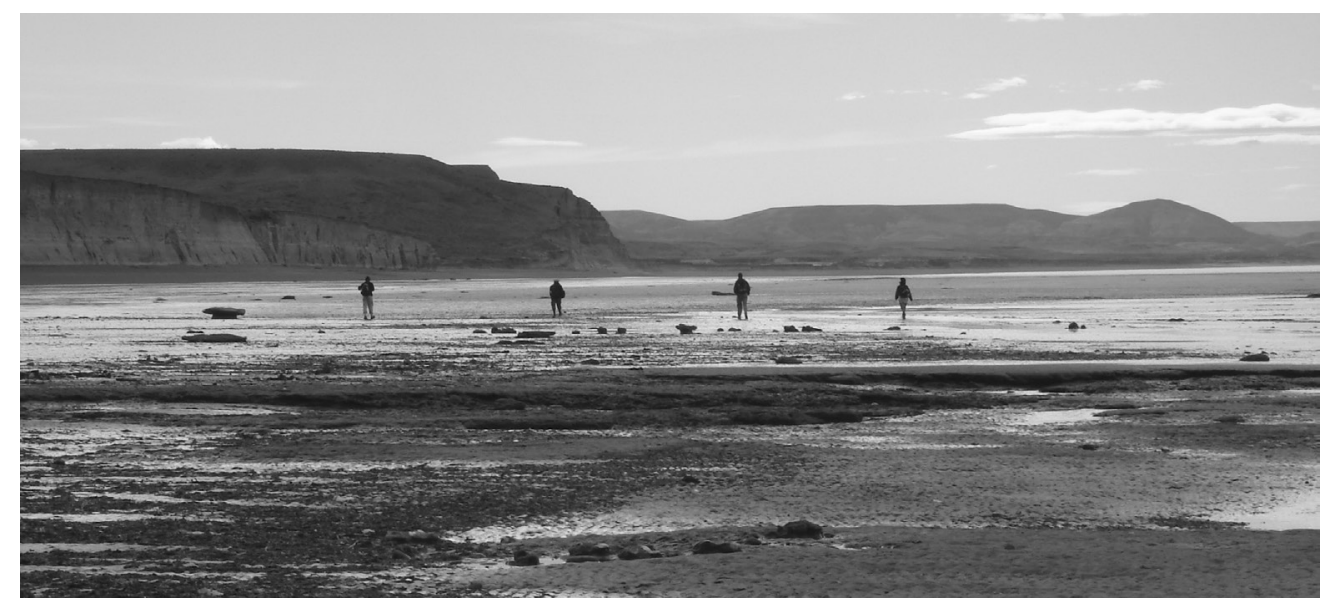

Figura 2. Prospección en una playa intermareal (foto PROAS).

intermareales), se disminuyó la distancia entre transectas. Por otro lado, unos pocos sectores que presentaban dificultades o peligros para su acceso, tales como grietas de gran extensión en las planicies de abrasión que impedían el paso, no pudieron ser prospectados. Asimismo, en los contados casos de playas o restingas sin acceso, se realizaron recorridos por el techo de los acantilados a fin de realizar observaciones con prismáticos. Por último, en los casos en los que las características del registro arqueológico permitieran estimar como altamente probable la presencia de material en estratigrafía, se utilizaron también detectores de metales.

De acuerdo a lo ya señalado, el objetivo de los relevamientos consistió en registrar evidencia arqueológica de embarcaciones naufragadas o abandonadas. Esto incluía embarcaciones con diverso grado de integridad, para lo cual se establecieron las siguientes categorías:

- $\quad$ Estructura completa

- $\quad$ Fragmento o parte de estructura

- Componente estructural desarticulado

Se decidió registrar únicamente aquellos materiales que presentaban evidencias claras de un origen náutico, independientemente de su integridad o estado de preservación. Otro tipo de evidencia de interés a ser registrada estaba conformada por elementos que podrían haber formado parte del equipamiento o cargamento de embarcaciones.
Asimismo, en relación a la distribución espacial de los materiales y a los fines de un primer ordenamiento para su análisis posterior, se establecieron dos categorías de hallazgos en función de la frecuencia: conjunto y hallazgo aislado. El criterio para definir un conjunto -determinado en forma arbitraria- fue que agrupara materiales cuya separación entre ellos fuera menor a $1.000 \mathrm{~m}$. Este criterio fue establecido en función de la gran dispersión que habitualmente presenta el registro arqueológico de naufragios en costas oceánicas de elevada dinámica y en relación a la gran extensión del área a relevar (40 km de línea costera) ( $c f$. Russell, 2005).

La posición de cada hallazgo fue registrada con GPS. En los casos en que se encontraron materiales acumulados con una dispersión menor a la resolución del receptor GPS utilizado (aproximadamente $10 \mathrm{~m}$ ) se registró el centro geométrico de la concentración. Se tomaron fotografías tanto de los hallazgos como del contexto de depositación y se caracterizó el emplazamiento.

Ante el hallazgo de restos de naufragios se registraron sus características generales (materias primas, tipología, dimensiones) que permitieran obtener información diagnóstica (ver sección siguiente). Se realizaron croquis en los casos en los que se consideró pertinente para complementar la caracterización o bien para registrar la distribución de los hallazgos. Por último, se registraron observaciones vinculadas al estado de preservación y a riesgos de alteración.

En ningún caso se realizaron recolecciones. 
Sólo se tomaron muestras de elementos representativos y potencialmente diagnósticos para una aproximación a la caracterización e identificación cronológica-cultural de los restos. Estos resultaron ser siempre de madera o metal.

\section{Principales indicadores para la} interpretación de restos de embarcaciones

A menudo, los restos de naufragios se presentan sin evidencia de su cargamento $\mathrm{u}$ otros elementos transportados, por lo que su interpretación debe basarse exclusivamente en restos del casco, aparejo y/o equipamiento.

Para conocer el tamaño de una embarcación, su función, el material principal con que fue construido el casco (madera, metal o mixto), su sistema de propulsión, su cronología y origen cultural existen diversos indicadores. Los mismos pueden utilizarse para embarcaciones con distinto grado de integridad, o incluso para restos desarticulados (McKee, 1976; Steffy, 1994; Russell, 2005, entre otros).

De acuerdo con Russel (2005), el análisis sistemático de los restos arqueológicos desarticulados debe focalizarse, en primer lugar, en distinguir entre los elementos observados cuáles son las piezas estructurales. A continuación, a partir de sus características, buscar identificarlas para definir de qué tipo de componente se trata. Esto, a su vez, puede aportar información acerca de las características de la embarcación de la cual formaban parte.

Con respecto al tamaño de una embarcación, las dimensiones de los componentes principales de la estructura del casco (como cuadernas, quilla, sobrequilla), de los elementos de unión y de las de piezas del equipamiento (tales como anclas, cadenas o molinetes) constituyen indicadores útiles, ya que guardan proporción con el barco.

Para evaluar la función o uso de una embarcación (guerra, carga, pesca, etc.), puede resultar diagnóstica la tecnología empleada en la construcción del casco, así como la presencia de armamento o equipamiento específico.

3 En el caso de materiales orgánicos, también pueden utilizarse métodos de datación absoluta, como el C14 y, particularmente para la madera, la dendrocronología. Sin embargo, uno y otro presentan sus limitaciones. En cuanto al C14, esto es debido a que la fecha resultante se expresa en un intervalo que puede ser de poca utilidad en lo que
Piezas de arboladura (palos, vergas, zunchos), elementos de jarcia (motones, vigotas), calderas, hélices, máquinas de vapor o motores permiten definir el sistema de propulsión, que puede ser a vela, mecánico (vapor, motor) o mixto (vela-vapor, vela-motor).

Con respecto a la cronología de una embarcación, entre los indicadores de mayor potencial diagnóstico se encuentra la presencia de determinados materiales y rasgos tecnológicos y tipológicos, lo cual puede aplicarse tanto a piezas estructurales como a elementos de unión y equipamiento ${ }^{3}$. Ejemplo de ello son el uso de ciertas aleaciones metálicas en la elaboración de elementos de clavazón o de chapas de recubrimiento del casco, o los sistemas empleados para unir las piezas estructurales (cabillas, clavos, pernos, remaches, soldadura), cuyo desarrollo e implementación en la navegación están suficientemente documentados.

Finalmente, el origen cultural de una embarcación puede ser inferido a partir de su tradición constructiva, como así también del empleo de determinadas materias primas. Por ejemplo, este último puede ser el caso de grupos taxonómicos de maderas cuya distribución geográfica puede ser identificada. No obstante, en este sentido también debe considerarse que si bien en la construcción naval por lo general se utilizaban recursos locales, en algunos casos se ha recurrido a la obtención de maderas de otros lugares, ya sea por razones de escasez o bien por preferencias hacia ciertas especies.

\section{RESULTADOS}

\section{Relevamientos costeros}

Los relevamientos realizados dieron como resultado la identificación de hallazgos claramente atribuibles a embarcaciones. Estos comprenden varios de los elementos que habían sido localizados o descriptos previamente por otras personas y otros de los cuales no se tenía conocimiento previo. Los materiales hallados son principalmente piezas

respecta a tiempos históricos recientes. En lo que respecta a la dendrocronología, si bien permite obtener fechados de definición anual, el método requiere de una serie de condiciones que no siempre son posibles de obtener (ver, por ejemplo, English Heritage, 2004). 


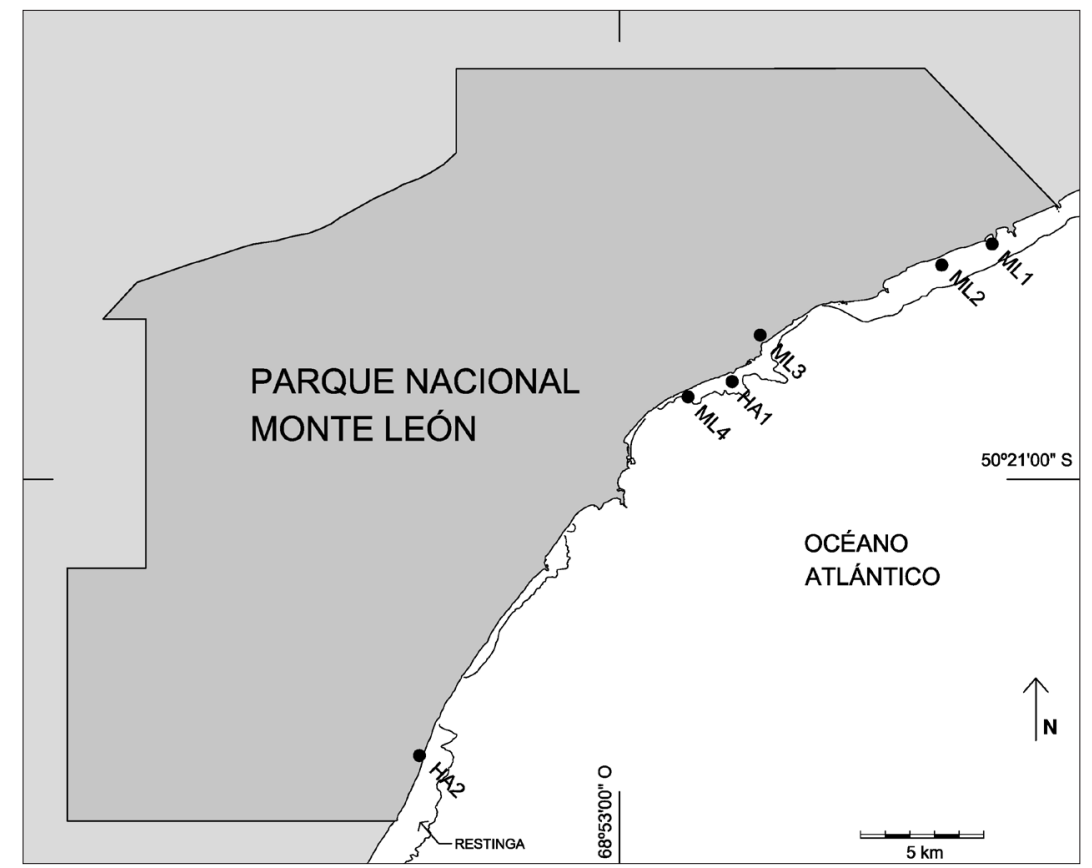

Figura 3. Mapa del PNML con la ubicación de los conjuntos y los hallazgos aislados (dibujo C. Murray).

estructurales desarticuladas y fragmentos diversos localizados en forma dispersa. En su mayor parte están elaborados en madera y, en menor medida, en metal (hierro o acero, cobre y/o aleaciones de cobre). En ningún caso se localizaron estructuras completas o partes de ellas, ni tampoco otros materiales que pudiesen ser asignados a su cargamento o equipamiento

En cuanto a su localización, se observó que los materiales se encuentran distribuidos en forma discontinua a lo largo de la costa, variando también en su frecuencia. Así, mientras en algunos sectores la ocurrencia de hallazgos presenta una mayor densidad que en otros, en determinadas áreas no se localizó resto alguno. Como resultado de las prospecciones se identificaron tres conjuntos (denominados ML1-2, ML3 y ML4), así como dos hallazgos aislados (HA1 y HA2) (Fig. 3). Las características de cada uno de ellos se describen a continuación:

\section{a) ML1-2}

Este conjunto está localizado cerca del límite norte del PNML. Los materiales están distribuidos en la playa de una pequeña bahía (subsector denominado ML1) y la playa longilínea contigua que se extiende hacia el SO de la anterior (subsector ML2).

En el primer caso, los materiales hallados consisten en alrededor de 60 artefactos distribuidos en su mayor parte dentro de una franja de cerca de $100 \mathrm{~m}$ de ancho, a lo largo de la línea de resaca correspondiente a eventos de tormenta, en el límite entre las zonas intermareal y surpramareal (Fig. 4). Alli fueron identificados componentes estructurales de madera, tales como curvas, cuadernas, baos y posiblemente un codaste, como así también pequeños fragmentos de chapa de cobre o aleación de cobre del tipo utilizado para recubrir el forro de cascos de madera (Tabla 2). Todos los componentes estructurales se encontraron desarticulados.

En la playa contigua se localizaron 75 artefactos distribuidos a lo largo de $3,5 \mathrm{~km}$, tanto en las zonas intermareales como supramareales (Tabla 2 y Figs. 5 a 10). Este conjunto está conformado por componentes estructurales de madera, como curvas, cuadernas, tablas de forro y una pieza de arboladura, como así también por un molinete, cadenas, fragmentos de chapa de cobre o aleación de cobre y otros elementos. Asimismo, el conjunto incluye muchos otros maderos que poseen evidencia de origen náutico, pero cuya función específica no pudo ser determinada fehacientemente debido 


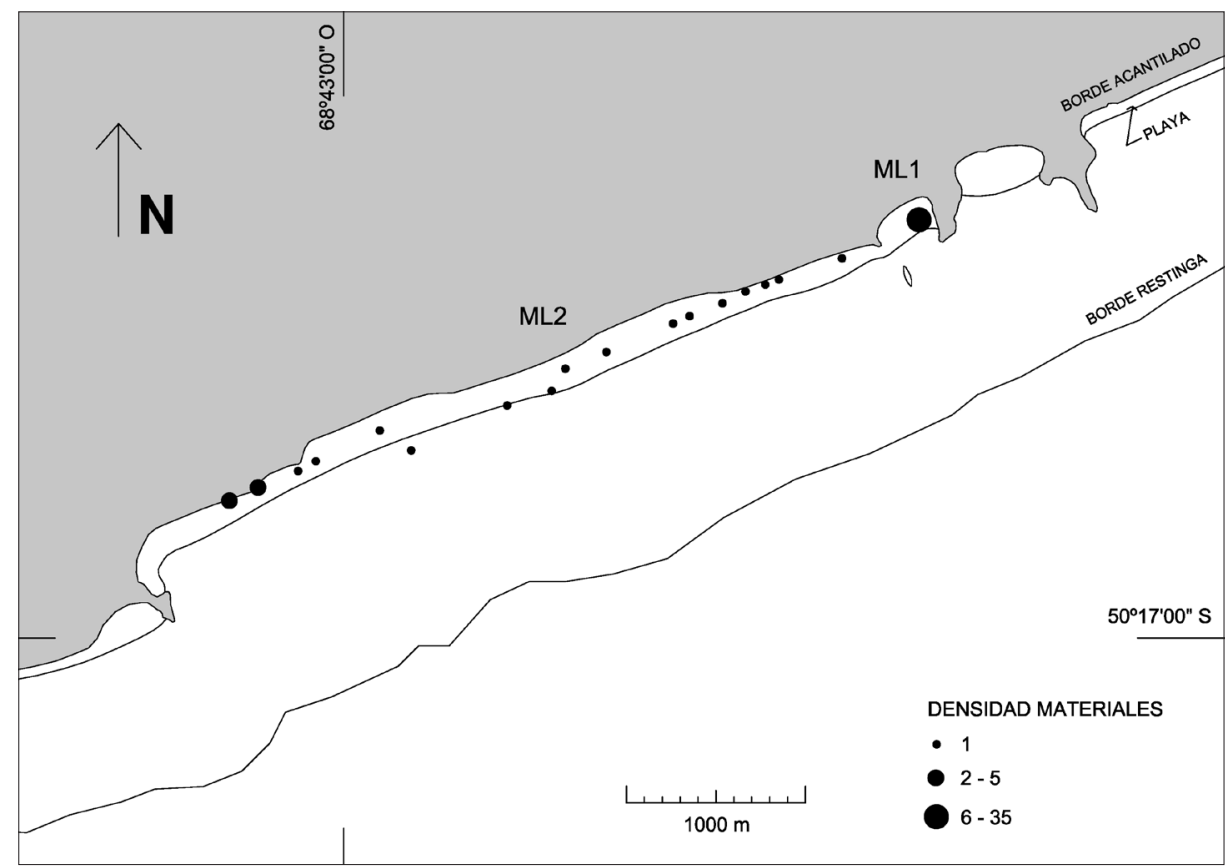

Figura 4. Distribución de los materiales del conjunto ML1-2 (dibujo C. Murray).

al mal estado de preservación que presentan. Los componentes estructurales se encontraron desarticulados, a excepción de cuatro elementos unidos con clavazón metálica.

Cabe señalar que las cadenas, algunos elementos de hierro y la mayoría de las chapas de cobre o aleación de cobre se hallaron con detector de metales, ya que se encontraban bajo el sedimento.

\section{b) ML3}

Este grupo de materiales fue localizado accidentalmente fuera del área de prospección, mientras se transitaba por el techo de un acantilado sin acceso a la playa. Su característica más peculiar es su localización, a unos $100 \mathrm{~m}$ de la costa y a una altura promedio de $22 \mathrm{msnm}$. Los restos consisten en una decena de piezas de madera de origen náutico (Tabla 3 y Fig. 11).

\section{c) ML4}

Consiste en 11 elementos distribuidos a lo largo de $3 \mathrm{~km}$ de costa, ubicados en su mayor parte en la base del acantilado y sobre la restinga, en la zona superior del intermareal. Todos los materiales son de hierro, a excepción de una de las piezas que también tiene componentes de madera (Tabla 4 y Figs. 11 y 12).

\section{d) Hallazgos aislados}

Uno de los hallazgos (HA1) se encontró en el área denominada Restinga Norte, entre los conjuntos ML3 y ML4. Consiste en un tramo de cadena apilada de aproximadamente $20 \mathrm{~m}$ de longitud asociado a un escobén de hierro de entre 22 y $24 \mathrm{~cm}$ de diámetro interno (Fig. 13). Los eslabones de la cadena poseen contrete y el diámetro de su barra es de $34 \mathrm{~mm}$. El otro hallazgo aislado (HA2) fue localizado en el sector sur del PNML y consiste en una ligazón de una cuaderna de madera similar a las halladas en ML1-2. Posee orificios de clavazón, pernos de hierro y cabillas.

\section{Identificación de materiales}

Las identificaciones anatómicas de maderas fueron realizadas en el Laboratorio de Anatomía Vegetal de la Facultad de Ciencias Exactas y Naturales de la Universidad de Buenos Aires (UBA) utilizando microscopía electrónica de barrido 
Tabla 2. Hallazgos en ML1-2

Piezas estructurales

\begin{tabular}{|c|c|c|c|}
\hline Elemento & Material principal & $\mathrm{N}$ & Descripción y observaciones \\
\hline $\begin{array}{l}\text { Parte de } \\
\text { cuaderna (ligazón, } \\
\text { varenga) }\end{array}$ & Madera & 16 & $\begin{array}{l}\text { Con orificios de clavazón y, en varios casos, pernos de hierro y/o } \\
\text { cabillas; la mayoría tienen una sección de alrededor de } 25 \times 30 \mathrm{~cm}\end{array}$ \\
\hline Curva & Madera & 8 & Con orificios de clavazón y pernos de hierro \\
\hline Forro exterior & Madera & 9 & $\begin{array}{l}\text { Con orificios de clavazón y, en algunos casos, con cabillas; algunas } \\
\text { piezas poseen tachuelas para fijación del recubrimiento (el metal } \\
\text { de una de ellas identificada como zinc y el de otra como bronce); el } \\
\text { espesor de las tablas es de alrededor de } 7 \mathrm{~cm}\end{array}$ \\
\hline $\begin{array}{l}\text { Posible quilla o } \\
\text { sobrequilla }\end{array}$ & Madera & 1 & $\begin{array}{l}\text { Con pernos de aleación de cobre (una muestra se identificó como } \\
\text { latón) y cabillas }\end{array}$ \\
\hline Posible codaste & Madera & 1 & $\begin{array}{l}\text { Con orificios de clavazón y pernos de hierro; sección de } 24 \text { x } 27 \\
\mathrm{~cm}\end{array}$ \\
\hline Posible bao & Madera & 2 & $\begin{array}{l}\text { Con orificios de clavazón y pernos de hierro; sección de } 20 \text { x } 25 \\
\mathrm{~cm}\end{array}$ \\
\hline $\begin{array}{l}\text { Posible durmiente } \\
\text { de cubierta }\end{array}$ & Madera & 1 & $\begin{array}{l}\text { Articulado con parte de una posible cuaderna; con pernos de } \\
\text { hierro y rebajes en una cara }\end{array}$ \\
\hline Posible bauprés & Madera & 1 & $\begin{array}{l}\text { Posee un zuncho de hierro circular con perno roscado; diámetro } \\
\text { de } 50 \mathrm{~cm}\end{array}$ \\
\hline $\begin{array}{l}\text { Pieza estructural } \\
\text { indeterminada }\end{array}$ & Madera & 57 & $\begin{array}{l}\text { La mayoría con orificios de clavazón; en algunos casos poseen } \\
\text { pernos de hierro y/o cabillas }\end{array}$ \\
\hline
\end{tabular}

Piezas no estructurales

\begin{tabular}{|c|c|c|c|}
\hline Elemento & Material principal & $\mathrm{N}$ & Descripción y observaciones \\
\hline $\begin{array}{l}\text { Molinete de } \\
\text { guimbalete }\end{array}$ & Madera y hierro & 1 & $\begin{array}{l}\text { Tambor octogonal de madera y diversas partes de hierro (eje, } \\
\text { ruedas de roquetes, rueda de freno y zunchos); diámetro del } \\
\text { tambor: } 58 \mathrm{~cm}\end{array}$ \\
\hline Cadena & Hierro & 3 & $\begin{array}{l}\text { Una es de eslabones con contrete y el diámetro de la barra de los } \\
\text { eslabones es de } 32 \mathrm{~mm} \text {; otra es de eslabones aparentemente sin } \\
\text { contrete, de } 18 \mathrm{~mm} \text { de diámetro; de la tercera no hay datos }\end{array}$ \\
\hline $\begin{array}{l}\text { Chapa de } \\
\text { recubrimiento }\end{array}$ & $\begin{array}{l}\text { Cobre o aleación de } \\
\text { cobre (dos muestras } \\
\text { fueron identificadas como } \\
\text { latón) }\end{array}$ & 33 & $\begin{array}{l}\text { Fragmentos de forma y tamaño irregular; varios con orificios de } \\
\text { clavado }\end{array}$ \\
\hline $\begin{array}{l}\text { Roldana de } \\
\text { motón }\end{array}$ & Madera & 2 & Con rebaje para cojinete metálico \\
\hline Fleje & Posible hierro galvanizado & 9 & Con dos remaches en la unión de los extremos \\
\hline Otros elementos & Madera, hierro & 6 & $\begin{array}{l}\text { Una duela de tonel, un fragmento de cable trenzado, un fleje } \\
\text { metálico, una barra con cáncamo y dos piezas indeterminadas }\end{array}$ \\
\hline
\end{tabular}

Notas:

- Sólo se consignan dimensiones de elementos considerados diagnósticos del tamaño de la embarcación y que conservan dimensiones cercanas a las originales. En algunos casos las medidas son aproximadas.

- El término "hierro" se utiliza aquí de manera genérica aún cuando en algunos casos pudiera tratarse de acero, una aleación de hierro y carbono más resistente que el hierro cuyo uso en la construcción naval comenzó a sustituir al hierro a partir de la década de 1860 (McCarthy, 1985). 


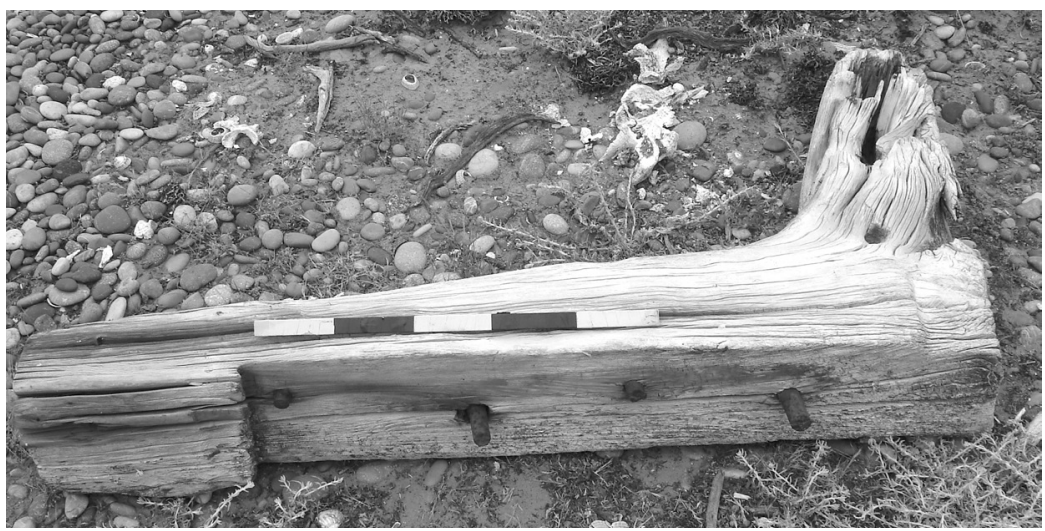

Fig. 5. Curva ML1-2. Escala $50 \mathrm{~cm}$ (foto PROAS).

Fig. 6. Forro exterior ML2-38

con tachuelas

de zinc (detalle).

Escala $22 \mathrm{~cm}$ (foto

PROAS).

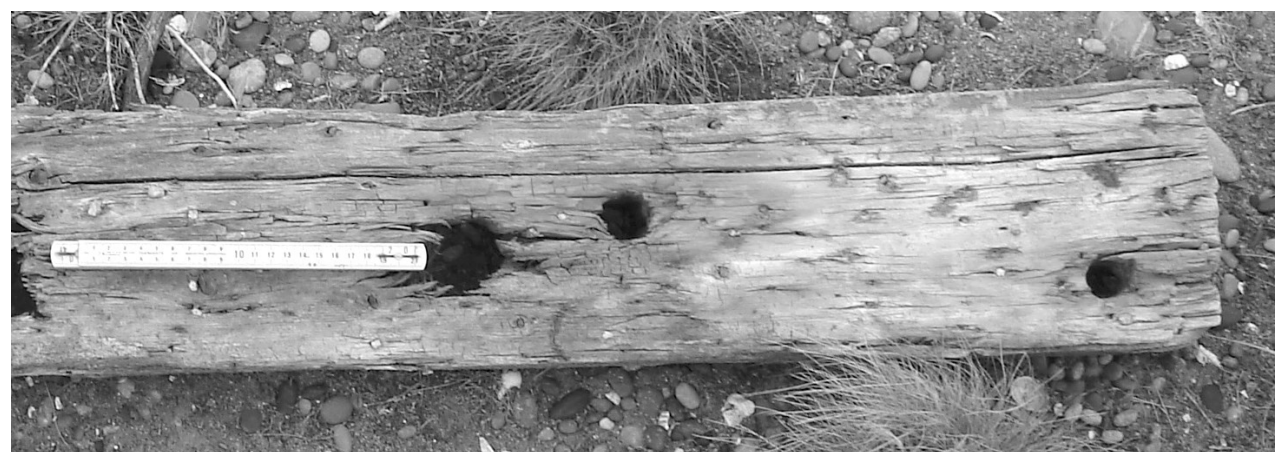

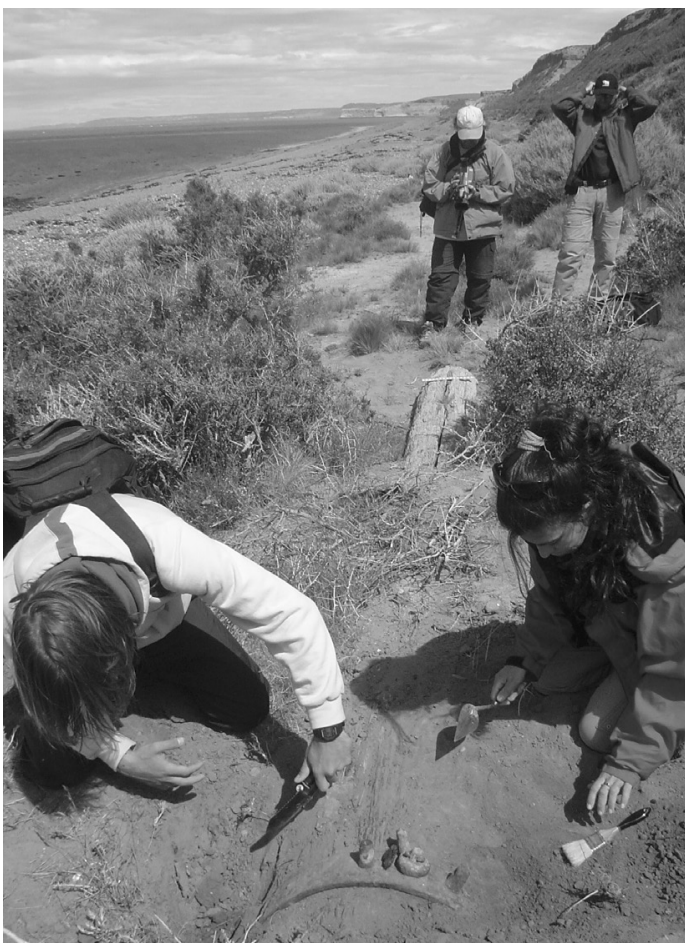

Fig. 8. Posible bauprés ML2-09 con zuncho de hierro (foto PROAS).

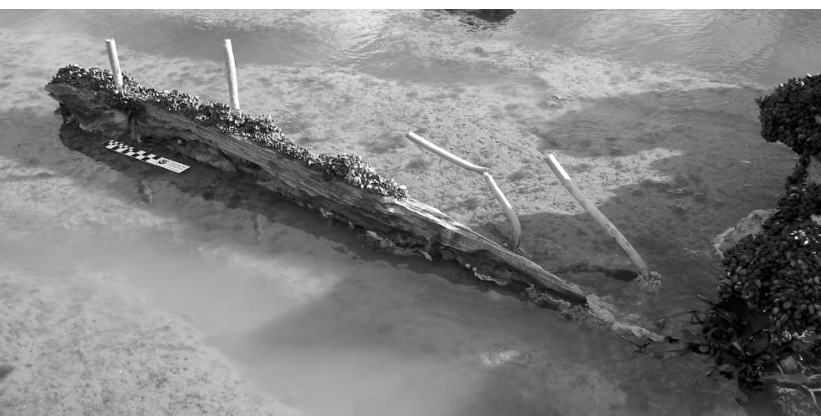

Fig. 7. Posible quilla o sobrequilla ML2-55. Escala $20 \mathrm{~cm}$ (foto PROAS).

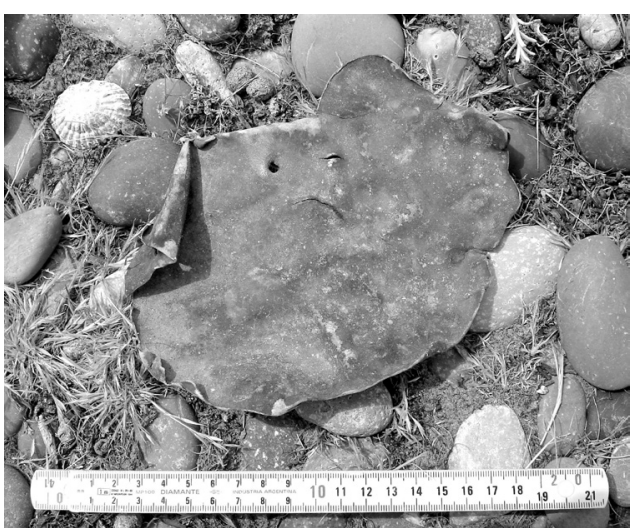




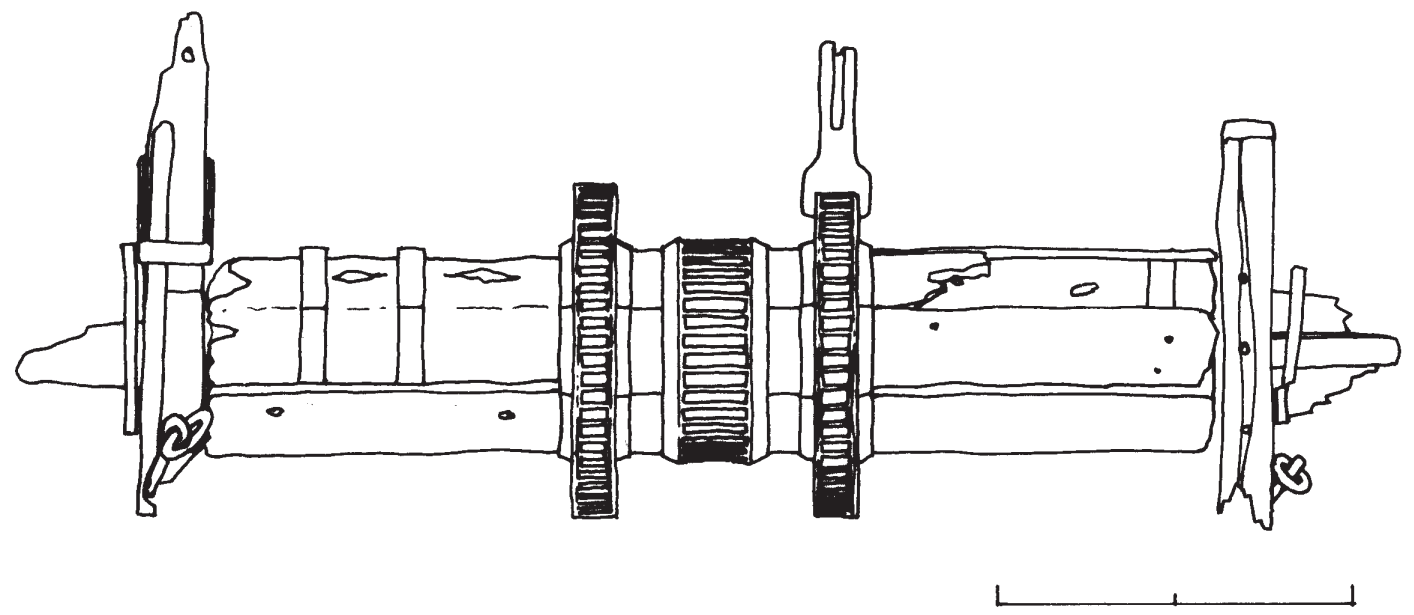

Fig. 10. Molinete ML2-54. Escala $1 \mathrm{~m}$ (dibujo C. Murray).

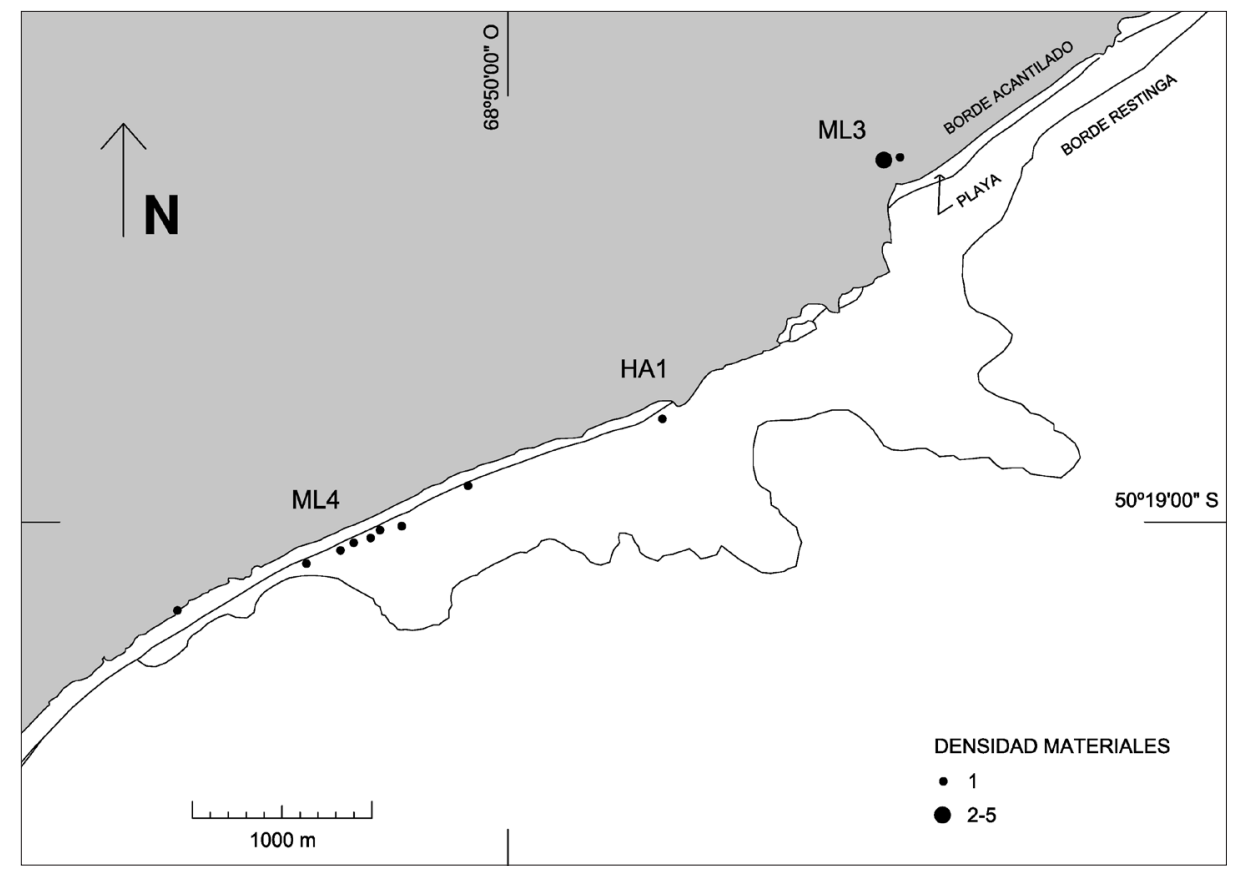

Figura 11. Distribución de los materiales de los conjuntos ML3 y ML4 (dibujo C. Murray).

Tabla 3. Hallazgos en ML3.

\begin{tabular}{llll}
\hline \multicolumn{1}{c}{ Elemento } & $\begin{array}{l}\text { Material } \\
\text { principal }\end{array}$ & $\mathrm{N}$ & Descripción y observaciones \\
\hline Posible curva coral & Madera & 1 & Con pernos y clavos de hierro \\
\hline $\begin{array}{l}\text { Posible forro } \\
\text { exterior }\end{array}$ & Madera & 2 & $\begin{array}{l}\text { Con orificios para cabillas y tachuelas de zinc para fijación de recubrimiento; el } \\
\text { espesor de las tablas es de } 7 \mathrm{~cm}\end{array}$ \\
\hline $\begin{array}{l}\text { Pieza } \\
\text { indeterminada }\end{array}$ & Madera & 7 & Algunos con orificios y otros con orificios y cabillas \\
\hline
\end{tabular}

\footnotetext{
Ver notas al pie de Tabla 2.
} 


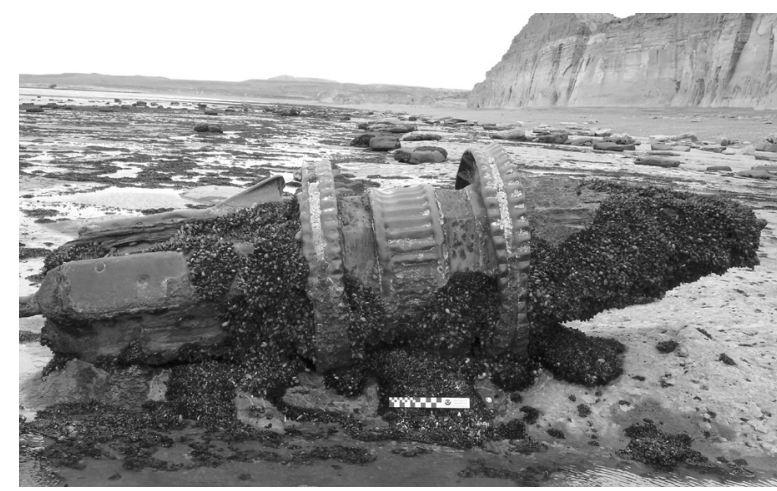

Figura 12. Molinete ML4-05. Escala $20 \mathrm{~cm}$ (foto PROAS).

ambiental (Electroscan 2010) (Tabla 5). Cabe señalar que la identificación taxonómica a partir de la estructura anatómica de la madera posee en algunos casos limitaciones que sólo permiten alcanzar el nivel de género o subgrupos (Newsom y Miller, 2009). Restricciones adicionales pueden surgir en función del estado de preservación en que se encuentra la madera.

Por su parte, los análisis de muestras metálicas se llevaron a cabo en el Laboratorio de Materiales de la Facultad de Ingeniería de la UBA. La composición química elemental del material se determinó por espectroscopia de rayos $\mathrm{X}$ dispersiva en energía (EDXRS), mientras que en algunas muestras se realizaron además análisis metalográficos utilizado microscopía óptica y electrónica de barrido (Tabla 6).

\section{Materiales previamente recuperados}

Los materiales de origen náutico recolectados por pobladores de Puerto Santa Cruz y Comandante

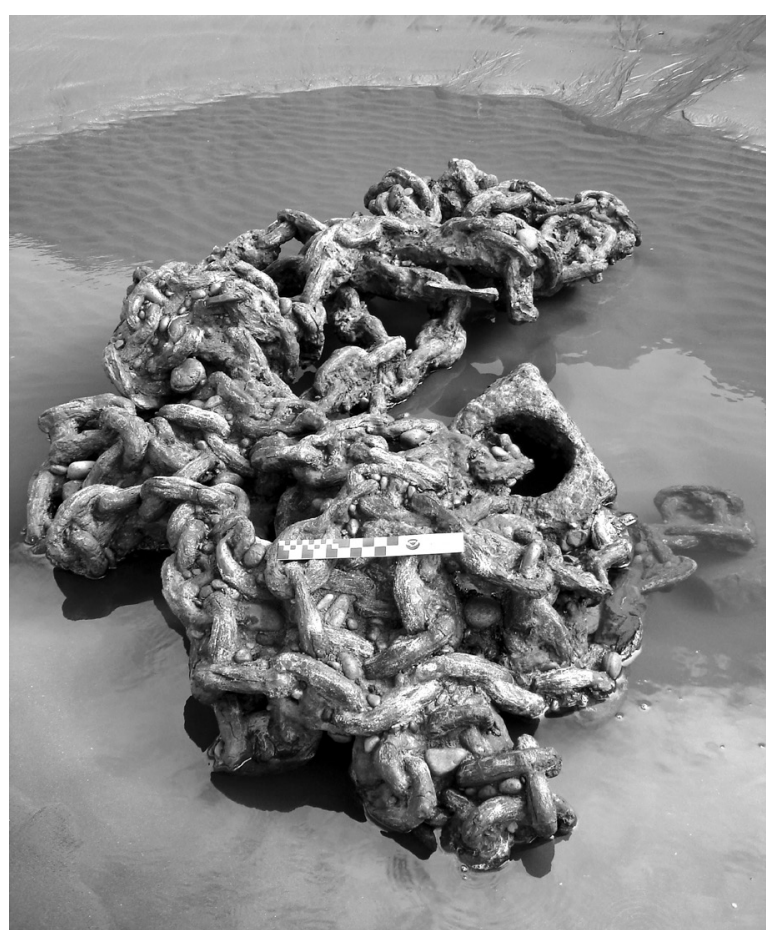

Figura 13. Tramo de cadena con escobén HA1. Escala $20 \mathrm{~cm}$ (foto PROAS).

Luis Piedra Buena en años anteriores a este estudio consisten principalmente en elementos estructurales y otras piezas correspondientes a embarcaciones de madera. Debido a que estos elementos se encontraban descontextualizados, sólo se realizó un registro general descriptivo y fotográfico de cada uno de ellos. En los casos en que fue posible se realizó la identificación del tipo de elemento y su cronología estimada.

Entre las piezas que no presentaban rasgos diagnósticos en cuanto a su cronología, se hallaba

Tabla 4. Hallazgos en ML4.

\begin{tabular}{|c|c|c|c|}
\hline Elemento & Material principal & $\mathrm{N}$ & Descripción y observaciones \\
\hline Posible curva & Hierro & 2 & Con orificios \\
\hline $\begin{array}{l}\text { Molinete de } \\
\text { guimbalete }\end{array}$ & Madera y hierro & 1 & $\begin{array}{l}\text { Tambor octogonal de madera y diversas partes de hierro (eje, ruedas } \\
\text { de roquetes, rueda de freno y guardainfantes); diámetro del tambor } \\
\text { medido en el sector medio: } 55 \mathrm{~cm}\end{array}$ \\
\hline Cable trenzado & Hierro & 1 & Seccionado en varios tramos; posiblemente parte de la jarcia fija \\
\hline $\begin{array}{l}\text { Pieza } \\
\text { indeterminada }\end{array}$ & Hierro & 7 & No corresponden a piezas estructurales \\
\hline
\end{tabular}

Ver notas al pie de Tabla 2. 
Tabla 5. Identificación botánica de muestras de madera (tomado de Castro, 2007).

\begin{tabular}{|c|c|c|c|c|}
\hline $\begin{array}{l}\text { Código } \\
\text { de pieza }\end{array}$ & Artefacto & Nombre científico & Nombre vulgar & Distribución geográfica \\
\hline $\begin{array}{l}\text { ML1-03- } \\
\text { MM6 }\end{array}$ & Posible ligazón & \multirow{4}{*}{$\begin{array}{l}\text { Afin a Pinus silvestris L. y } \\
\text { Pinus resinosa Aiton } \\
\text { (Pinaceae) (Philips, 1941) }\end{array}$} & \multirow{4}{*}{$\begin{array}{l}\text { Pino escocés (scots pine, } \\
\text { Scotch pine, common pine, } \\
\text { red pine, Baltic redwood) } \\
\text { y pino rojo (red pine), } \\
\text { respectivamente }\end{array}$} & \multirow{4}{*}{$\begin{array}{c}\text { Europa, Asia Menor, el } \\
\text { Cáucaso, Siberia, Amur hasta } \\
\text { 70² lat. N (Greguss, 1955; } \\
\text { USDA, 1965) } \\
\text { y America del Norte (Philips, } \\
\text { 1941), respectivamente }\end{array}$} \\
\hline $\begin{array}{l}\text { ML1-28- } \\
\text { MM8 }\end{array}$ & Forro exterior & & & \\
\hline $\begin{array}{l}\text { ML2-09- } \\
\text { MM1 }\end{array}$ & Posible bauprés & & & \\
\hline $\begin{array}{l}\text { ML2-10- } \\
\text { MM1 }\end{array}$ & Posible cuaderna & & & \\
\hline $\begin{array}{l}\text { ML1-06- } \\
\text { MM1 }\end{array}$ & Cabilla & $\begin{array}{c}\text { Afín a Fagus sp (Fagaceae) (ver } \\
\text { Newson \& Miller, 2009) }\end{array}$ & Haya (beech) & $\begin{array}{c}\text { Europa, este de Asia, este de } \\
\text { America del Norte y México } \\
\text { (Record \& Hess, 1943; Tubbs } \\
\text { \& Huston, 1990) }\end{array}$ \\
\hline $\begin{array}{l}\text { ML1-06- } \\
\text { MM2 }\end{array}$ & Ligazón & $\begin{array}{c}\text { Afín a Betula verrucosa } \\
\text { Ehrh. (Betula alba L.; Betula } \\
\text { pendula Roth.) (Betulaceae) }\end{array}$ & $\begin{array}{l}\text { Abedul (silver birch, Swedish } \\
\text { birch, English birch) }\end{array}$ & $\begin{array}{c}\text { Europa y Asia Menor (Parodi, } \\
1972)\end{array}$ \\
\hline $\begin{array}{l}\text { ML1-23- } \\
\text { MM7 }\end{array}$ & Curva & \multirow{3}{*}{$\begin{array}{c}\text { Afín al grupo (Picea-Abies- } \\
\text { Larix) } \\
\text { Coniferae - Pinaceaae - Picea } \\
\text { spp. } \\
\text { Afín a Picea abies (L.) Karst } \\
\text { (Picea excelsa Link) } \\
\text { (Greguss, 1955) }\end{array}$} & \multirow{3}{*}{$\begin{array}{c}\text { Abeto (common spruce, } \\
\text { spruce) }\end{array}$} & \multirow{3}{*}{$\begin{array}{c}\text { Europa septentrional y central, } \\
\text { Asia septentrional (Greguss, } \\
\text { 1955) }\end{array}$} \\
\hline $\begin{array}{l}\text { ML2-38- } \\
\text { MM1 }\end{array}$ & $\begin{array}{l}\text { Posible forro } \\
\text { exterior }\end{array}$ & & & \\
\hline $\begin{array}{l}\text { ML3-01- } \\
\text { MM1 }\end{array}$ & $\begin{array}{l}\text { Posible forro } \\
\text { exterior }\end{array}$ & & & \\
\hline $\begin{array}{l}\text { ML2-11- } \\
\text { MM1 }\end{array}$ & $\begin{array}{l}\text { Posible cuaderna } \\
\text { o sección baja del } \\
\text { codaste }\end{array}$ & \multirow{4}{*}{$\begin{array}{c}\text { Afín al subgrupo de especies de } \\
\text { robles de hojas caducas. Incluye } \\
\text { entre otras especies: Quercus } \\
\text { robur L., Q. petraea Liebl, Q. } \\
\text { pubescens Willd (*), y } \\
\text { Q. Alba L }\left(^{* *}\right) \text { (cf. Newson \& } \\
\text { Miller, 2009) }\end{array}$} & \multirow{4}{*}{$\begin{array}{l}\text { Roble, roble inglés común, } \\
\text { roble europeo o roble de } \\
\text { Eslavonia (English oak); roble } \\
\text { albar y roble pubescente, } \\
\text { respectivamente }\end{array}$} & \multirow{4}{*}{$\begin{array}{c}\text { (*) Europa (Parodi, 1972) } \\
\text { y (**) Norte America } \\
\text { (Newson \& Miller, 2009), } \\
\text { respectivamente. }\end{array}$} \\
\hline $\begin{array}{l}\text { ML2-54- } \\
\text { MM1 }\end{array}$ & Molinete & & & \\
\hline $\begin{array}{l}\text { ML2-55- } \\
\text { MM4 }\end{array}$ & $\begin{array}{l}\text { Posible quilla o } \\
\text { sobrequilla }\end{array}$ & & & \\
\hline $\begin{array}{l}\text { ML4-05- } \\
\text { MM1 }\end{array}$ & Molinete & & & \\
\hline
\end{tabular}

una vigota de madera de tres ojos, la cual se encontraba bastante deteriorada. Este elemento resultaba de especial interés para miembros de la comunidad local, quienes consideraban que podía pertenecer a la nao Santiago. Fue por ello que se procedió su identificación botánica, la cual indicó que estaba elaborada con madera de Tabebuia ipe (n. v. lapacho). Las implicancias de esto se discuten más abajo.

Gran parte de los materiales reunidos por los pobladores locales se encontraban depositados en el Museo Municipal Carlos Borgialli, de la ciudad de Puerto Santa Cruz. Con respecto a estos materiales -poco menos de 60 piezas-, se realizó un inventario donde se registraron los siguientes datos: identificación, materiales constitutivos, dimensiones generales, características y estado general de preservación. Este inventario fue ingresado en los archivos del museo y también formó parte de la documentación requerida por la Administración de Parques Nacionales. La Tabla 7 presenta en forma sintética 
Tabla 6. Análisis metalográficos (tomado de De Rosa, 2007).

\begin{tabular}{llc}
\multicolumn{1}{c}{$\mathrm{N}^{\circ}$ de identificación } & \multicolumn{1}{c}{ Muestra } & Resultados (\% en peso) \\
\hline ML1-MM8 & Chapa indeterminada & Aleación mayoritaria de zinc (Zn 94\% y Pb 6\%) \\
\hline ML1-MM3 & Chapa de recubrimiento de forro & Latón (Cu 61\%, Zn39\%) \\
\hline ML2-MM6 & Chapa de recubrimiento de forro & Latón (Cu 61\%, Zn 39\%) \\
\hline ML2-38-MM2 & Tachuela & Zinc (ca. 100\%) \\
\hline ML3-01-MM2 & Tachuela (fragmentos) & Zinc (ca. 100\%) \\
\hline ML2-55-MM9 & Perno & Latón (Cu-Zn) \\
\hline ML1-28-M9 & Tachuela & Bronce (Cu-Sn) \\
\hline
\end{tabular}

la información recopilada sobre los materiales recolectados previamente por pobladores locales.

Estado de preservación y riesgos de alteración

Los restos relevados en el PNML, tal como ya se ha señalado, se encuentran en su gran mayoría desarticulados y distribuidos en forma dispersa. Se observan en ellos signos de deterioro vinculados a procesos erosivos, degradación biológica y corrosión. Cuando los procesos de deterioro se encuentran muy avanzados la pérdida de rasgos morfológicos dificulta la identificación de las piezas. La acción de los diversos procesos y agentes intervinientes está estrechamente relacionada con la dinámica costera del PNML, en la que la intensidad del viento, la energía de las olas y el rango de mareas tienen un rol relevante.

De acuerdo al tipo de material y en función de su emplazamiento pueden destacarse ciertas particularidades. Los elementos de madera que se encuentran en sectores supramareales presentan, en grado variado, agrietamientos, desprendimientos de material y pérdida de peso específico producto de procesos de deterioro físicoquímico. Las piezas de pequeñas dimensiones resultado de la fragmentación parecen ser aún más vulnerables a la degradación que los elementos de mayor tamaño. Por otro lado, se observa que los materiales que se encuentran semienterrados presentan frecuentemente un mejor estado de preservación que aquellos expuestos.

Los maderos localizados en la zona intermareal, en comparación con los descriptos anteriormente, parecen tener una mayor consistencia. En ciertos casos esto puede vincularse con procesos de impregnación de óxidos debido a la corrosión de elementos metálicos. En algunos de estos maderos se han registrado alteraciones morfológicas importantes, probablemente ocasionadas por la erosión. Se ha observado en todos los materiales -en mayor o menor medidala presencia de organismos marinos adheridos a su superficie (biofouling), principalmente bivalvos mitílidos como Perumytilus purpuratus y Mytilus edulis chilensis (Bastida, com. pers.). Al menos en uno de los maderos se hallaron orificios causados por la actividad de organismos marinos perforantes de madera, lo cual ocasionó un importante daño físico a la pieza.

En lo que respecta a elementos de madera $y$ de metal ubicados en zonas de restinga, éstos suelen encontrarse entrampados entre las grietas o rocas; los elementos metálicos también pueden hallarse concrecionados y adheridos al sustrato.

Todos los elementos metálicos, tanto de sectores supramareales como intermareales, exhiben algún grado de corrosión. Además, aquellos localizados en sectores intermareales se caracterizan por su aspecto pulido, resultado de la erosión marina a la que se encuentran expuestos. Los elementos de cobre o aleación de cobre presentan por lo general oxidación superficial que no suele afectar la integridad del material. Los elementos de hierro ubicados en niveles superficiales o subsuperficiales a menudo forman concreciones.

En elementos de madera, independientemente de su estado de preservación y del sector 
Tabla 7. Hallazgos previos realizados en el área de estudio.

\begin{tabular}{|c|c|c|c|}
\hline Elemento & Material principal & $\mathrm{N}$ & Descripción y observaciones \\
\hline $\begin{array}{l}\text { Posible bita o cabirón } \\
\text { de molinete }\end{array}$ & Hierro & 1 & \\
\hline Zuncho & Hierro & 1 & Correspondiente a pieza de arboladura \\
\hline Roldana & Hierro & 1 & Con eje de hierro \\
\hline Ancla & Hierro & 2 & $\begin{array}{l}\text { Tipo Almirantazgo con cepo de hierro plegable (en una el cepo está } \\
\text { quebrado e incompleto); las longitudes máximas son de } 145 \mathrm{~cm} \text { y } \\
180 \mathrm{~cm} \text {, respectivamente }\end{array}$ \\
\hline $\begin{array}{l}\text { Parte de cuaderna } \\
\text { (posible varenga) }\end{array}$ & Madera & 1 & Con orificios de clavazón y cabilla \\
\hline Forro exterior & Madera & 2 & $\begin{array}{l}\text { Con tachuelas para fijación de recubrimiento; una de las piezas } \\
\text { posee un perno de cobre o aleación de cobre con arandela, un } \\
\text { orificio cuadrado con restos de corrosión de cobre y orificios de } \\
\text { cabillas y tiene un espesor de } 6 \mathrm{~cm}\end{array}$ \\
\hline $\begin{array}{l}\text { Sección de palo } \\
\text { (posible mastelero) }\end{array}$ & Madera & 1 & $\begin{array}{l}\text { Posee una caladura rectangular cerca de un extremo y un zuncho de } \\
\text { hierro con pernos roscados; largo total: } 7,28 \mathrm{~m}\end{array}$ \\
\hline Cabilla & Madera & 9 & Una posee hendiduras en cruz en uno de los extremos \\
\hline Perno & Hierro & 4 & \\
\hline Perno & $\begin{array}{l}\text { Cobre o aleación } \\
\text { de cobre }\end{array}$ & 1 & Sección redonda, con cabeza remachada y arandela \\
\hline Clavo & Hierro & 5 & De fuste cuadrado; longitud entre 12 y $20 \mathrm{~cm}$ \\
\hline $\begin{array}{l}\text { Chapa de } \\
\text { recubrimiento }\end{array}$ & $\begin{array}{l}\text { Cobre o aleación de } \\
\text { cobre }\end{array}$ & 14 & $\begin{array}{l}\text { Fragmentos de forma y tamaño irregular; varios con orificios de } \\
\text { clavado (uno con una tachuela in situ) }\end{array}$ \\
\hline Vigota & Madera & 2 & Con tres orificios; una de ellas posee zuncho de hierro \\
\hline Roldana & Madera & 2 & Con rebaje para cojinete metálico \\
\hline Posible duela & Madera & 1 & Con un lado curvo; correspondiente a la base de un contenedor \\
\hline $\begin{array}{l}\text { Tachuelas para fijación } \\
\text { de recubrimiento }\end{array}$ & $\begin{array}{l}\text { Cobre o aleación de } \\
\text { cobre }\end{array}$ & 4 & Fuste de sección cuadrada y cabeza redonda \\
\hline Cabo & Fibra vegetal & 1 & Fragmentos \\
\hline Pieza indeterminada & Madera & 8 & \\
\hline Pieza indeterminada & Hierro & 3 & \\
\hline
\end{tabular}

Ver notas al pie de Tabla 2.

de la costa en la que se localicen, se encuentran pernos, clavos (de hierro, zinc o aleaciones de cobre) y cabillas de madera in situ. En los casos en los que estas piezas de clavazón están ausentes, los orificios y los productos de corrosión constituyen evidencias de su uso.

Por último, cabe mencionar que los materiales localizados en el techo del acantilado
(ML3) se encuentran en un estado de preservación similar al de los materiales localizados en sectores supramareales.

Al considerar los principales riesgos de alteración que amenazan al registro arqueológico en el presente, puede señalarse que los materiales superficiales del sector supramareal se encuentran expuestos a la acción de diversos agentes (rayos 
solares, viento, spray marino), así como la ocasional acción de olas producidas por temporales extraordinarios, la cual puede además alterar su distribución. Con respecto a los materiales ubicados en la zona intermareal, la acción del biofouling y de los organismos perforantes de madera implican, junto con la erosión, una importante amenaza a su integridad. Asimismo, tal como se señaló anteriormente, su localización puede ser alterada por la acción de las mareas y el oleaje. Otro aspecto a considerar es el movimiento de sedimentos (arenas y gravas) por efecto de la dinámica costera la cual, por un lado, tiene efectos abrasivos en los materiales y, por otro, produce su exposición o enterramiento (Bastida et al. 2004; Grosso, 2008; Grosso et al. 2013).

En cuanto a las posibilidades de impacto antrópico, debe mencionase que si bien ciertos sectores de la costa del Parque son accesibles al público, al tratarse de un área protegida el riesgo de alteraciones de este tipo debiera ser mínimo.

\section{INTERPRETACIÓN Y DISCUSIÓN}

\section{Distribución y formación de los conjuntos}

Considerando lo señalado en las secciones precedentes, realizaremos algunas observaciones respecto de los materiales arqueológicos localizados en el PNML.

Por un lado, es interesante notar que los dos conjuntos principales (ML1-2 y ML4) están ubicados en sectores de la costa donde existen extensas restingas. Ello sugiere que la presencia de estos escollos podría tener relación con los eventos de naufragio que dieron origen a dichos restos.

En estos conjuntos se ha observado, asimismo, cierto patrón de distribución de materiales en relación a las geoformas y ambientes en donde se encuentran. Considerando la zonación de la costa con respecto a la marea, podemos señalar la presencia de material tanto en la zona intermareal como en la supramareal. El intermareal contiene una cantidad escasa de artefactos (aproximadamente el $10 \%$ del total hallado), constituidos por mayoría de piezas de hierro pesadas y unos pocos maderos inmovilizados en el sustrato rocoso. Estos materiales se encontraron en su totalidad en la franja superior de la restinga, muy cerca de la playa de canto rodado adyacente. Por su parte, los sectores más o menos horizontales del piso supramareal, y especialmente aquellos cercanos a la línea de resaca de temporales, se manifiestan como un área propensa a la depositación. Es aquí donde se encuentra la mayor parte de los restos de naufragios del PNML, y donde la diversidad de tamaño, peso y material es más notoria. Esta situación está seguramente vinculada con la alta energía del ambiente intermareal, lo que convierte a los sectores supramareales en áreas de depositación más estables. Asimismo, en función de la dinámica del intermareal, los materiales arqueológicos ubicados en la franja superior de esta zona pueden encontrarse periódicamente cubiertos por depósitos de canto rodado y/o arenas.

La presencia de piezas tales como molinetes y cadenas en el sector superior del intermareal, debido a su gran peso y tamaño, no puede ser explicada simplemente por la acción de las mareas y corrientes. Dado que estos elementos se asocian al sector de proa de las embarcaciones, es probable que hayan llegado hasta alli cuando aún formaban parte de la estructura de proa del barco naufragado. Otra alternativa es que se hayan producido, al menos en alguna medida, actividades de salvamento.

En base a lo antedicho, una posible explicación para la formación de los conjuntos ML1-2 y ML4 es que las embarcaciones hayan impactado contra el borde exterior de la restinga, lo que dio como resultado la fragmentación del casco. Mientras que algunas partes del casco se habrían depositado en el área del impacto, otras estructuras (incluyendo la proa) así como elementos desarticulados habrían sido desplazados y finalmente depositados en el sector superior del intermareal y el supramareal.

En el caso de los materiales hallados en ML3, su emplazamiento en lo alto del acantilado indica que fueron llevados hasta alli en forma intencional. En este sentido, cabe señalar que la recuperación o salvamento de restos náufragos ha sido una práctica recurrente a lo largo de la historia (Gibbs, 2006). Para las costas patagónicas se han citado varios antecedentes de dichas actividades, tanto por parte de grupos indígenas como de otros pobladores (ver, por ejemplo, Solari, 1992; Vázquez et al, 2011; Murray et al. 2012). Particularmente en la zona 
del actual PNML, debido a la escasez de especies leñosas de tamaño apropiado para ser utilizadas en construcciones o como combustible, los restos de madera de un naufragio habrian resultado muy atractivos. Si a ello se suman las recolecciones de materiales de origen náutico que se registraron en los últimos años en el PNML, puede estimarse la relevancia que la actividad antrópica ha tenido en la formación del registro arqueológico observado.

Por último, en lo que respecta a los materiales hallados en forma aislada (HA1 y HA2) y su posible asociación con los conjuntos identificados, se referirá a ello en la sección siguiente.

\section{Características de las embarcaciones representadas}

A partir de las características de los materiales relevados en el campo, una vez identificadas las piezas estructurales, se procedió a evaluar las asociaciones existentes entre ellos e identificar la tipología de las embarcaciones representadas. La evaluación de los elementos analizados indica, en primer lugar, que todos ellos (tanto los conjuntos como los materiales aislados) corresponderían a embarcaciones de características similares en cuanto a los materiales de construcción, la cronología, el tamaño y el sistema de propulsión. En relación a ello pudieron realizarse las observaciones que se detallan a continuación.

Con respecto a la construcción del casco, todos los materiales relevados indican que se trata de embarcaciones de madera. La evidencia que sustenta esto es que las piezas estructurales, así como los elementos correspondientes a la arboladura, son de dicho material. La única excepción la constituyen dos piezas de hierro que fueron identificadas preliminarmente como curvas, pero las mismas son del tipo de las utilizadas en embarcaciones con casco de madera. Esta afirmación se sostiene, además, por la ausencia de elementos estructurales metálicos.

En lo que respecta a la atribución cronológica de los materiales relevados, se identificaron diversos elementos cuya introducción y uso generalizado pueden ser asignados, sobre la base de su tipología y materia prima, al siglo XIX y cuyo uso, en algunos casos, se prolongó hasta principios del siglo XX. Estos son los molinetes de guimbalete (ML1-2 y ML4), las cadenas (ML1-2 y HA1), los cables de acero trenzado (ML4), los zunchos de hierro con pernos roscados en piezas de arboladura de madera (ML1-2) y las posibles curvas de hierro (ML4) (Stone, 1993). Cabe recordar aquí que dicha asignación cronológica coincide con las interpretaciones previas referidas a los materiales observados por Argüeso y Cazenave de la Roche en la misma área (ver apartado sobre intervenciones previas en el área). Por otro lado, los materiales recuperados previamente en la zona del PNML, también pueden situarse cronológicamente a partir del siglo XIX. Entre ellos se destacan dos anclas tipo Almirantazgo con cepo plegable de hierro, asî como los zunchos y roldanas de hierro. Es relevante mencionar que tanto entre los materiales relevados por nosotros, como aquellos de colecciones previas, se encontraban algunos que no pudieron ser asignados a un período particular debido a que no presentaban rasgos diagnósticos para tal fin, o bien en virtud de su mal estado de preservación.

Tal como se ha indicado, tanto en nuestros relevamientos en las áreas de ML1-2 como entre los materiales que forman parte de la colección del Museo Borgialli, de igual procedencia, se registraron fragmentos de chapas de cobre o aleación de cobre, materiales que comenzaron a ser utilizados para el recubrimiento de los cascos de madera en la segunda mitad del siglo XVIII (McCarthy, 2005). El análisis metalográfico realizado en las dos muestras recolectadas durante los relevamientos costeros reveló que se trata de un latón compuesto por un $61 \%$ de cobre y un $39 \%$ de zinc (De Rosa, 2007). Una aleación con proporciones semejantes es conocida como metal Muntz y fue patentada en 1832 (Bingeman et al. 2000). Asimismo, el empleo de aleaciones de cobre para elementos de clavazón, tal como las identificadas en un perno y una tachuela de ML1-2 (latón y bronce, respectivamente), también comenzó a registrarse en la segunda mitad del siglo XVIII (McCarthy, 2005).

Por otro lado, en ML2 y ML3 se observaron tachuelas de zinc clavadas en tablas de madera que probablemente correspondan a forro externo. Por su disposición y tamaño, estas tachuelas parecían corresponder a las utilizadas para sujeción de chapas de recubrimiento metálico del casco. Durante la primera mitad del siglo XIX en algunos países 
europeos y en los Estados Unidos se utilizaron chapas de zinc para recubrir el casco, aunque el material que terminó imponiéndose fue la aleación patentada por Muntz (Staniforth, 1985).

A fin de aproximarnos al tamaño de las embarcaciones representadas, se procedió en primer lugar a considerar las dimensiones de ciertas piezas diagnósticas correspondientes a la estructura, la arboladura y el equipamiento. Dado que la cronología de los hallazgos se había estimado en el siglo XIX, fue posible referirnos a fuentes contemporáneas para obtener información comparativa (por ejemplo, Lloyd's Register of British and Foreign Shipping [varios años]; Desmond, [1919] 1984). En función de ello se interpreta que las piezas mencionadas corresponden a embarcaciones medianas, de alrededor de 400 toneladas de arqueo.

Entre los materiales relevados hay algunos que constituyen indicadores del tipo de propulsión de las embarcaciones. En ML1-2 se identificaron una pieza de arboladura (un posible bauprés) y elementos de motonería (roldanas), los cuales remiten a embarcaciones propulsadas a vela. Asimismo, en ML4 se hallaron varios tramos de cables de hierro que posiblemente correspondan a la jarcia fija. Por otro lado, en la colección del Museo Borgialli también se hallaron elementos de arboladura (una sección de palo) y motonería (vigotas y roldanas). Cabe señalar que otros materiales que fueron recuperados por particulares hace varios años en zona del actual PNML (una sección de palo con roldana y zuncho) también apoyan esta interpretación, si bien no puede definirse con exactitud su lugar de proveniencia. Estos materiales fueron examinados a partir de imágenes fotográficas ya que al momento del relevamiento se encontraban en un avanzado estado de deterioro. Aunque los elementos mencionados también podrían encontrarse presentes en un barco de propulsión mixta, la ausencia de piezas vinculadas con sistemas de propulsión mecánica (tales como máquinas, calderas, hélices o chimeneas) no apoya esta hipótesis.

Con respecto a la función de las embarcaciones, la evidencia obtenida hasta el momento no es suficiente para extraer conclusiones. No obstante, cabe señalar que no se ha registrado la presencia de ningún tipo de material vinculado a armamento o pertrechos de guerra, con lo cual en principio podría interpretarse que no se trata de embarcaciones militares.

La información obtenida a partir de la identificación taxonómica de maderas de piezas correspondientes a la estructura y equipamiento de las embarcaciones, si bien se trata de un número limitado de muestras, nos permite analizar diversos aspectos. Tal como se observa en la Tabla 5 se han identificado diversos taxones para un mismo tipo de elemento estructural. Este es el caso tanto de componentes de cuadernas como de tablas de forro, ambos en el conjunto ML1-2. En principio, esto sugeriría que se encuentran representados distintos naufragios, ya que en una embarcación sería esperable el uso de un mismo taxón para cada tipo de componente estructural. Sin embargo, debe considerarse la posibilidad de que se hayan utilizado para la construcción diversas maderas de acuerdo a su disponibilidad, o bien que coexistan diversos taxones como resultado de reparaciones o modificaciones parciales.

La distribución geográfica de las maderas muestreadas en el campo indica que corresponden a especies originarias del hemisferio norte. De acuerdo al nivel de identificación obtenido, se registran algunos taxones originarios de Europa y ciertas regiones de Asia, así como otros que pueden ser originarios tanto de estas regiones como de América del Norte. En cuanto a la madera de la vigota recolectada previamente por pobladores locales, identificada como Tabebuia ipe, se trata de una especie nativa de Sudamérica tropical, sur de Brasil, Paraguay, noreste de Argentina y noroeste de Uruguay (Parodi, 1972). Este dato, sumado al hecho de que se trata de una pieza hallada entre un conjunto de materiales atribuidos al siglo XIX, y a que durante los relevamientos efectuados no se localizó ninguna pieza asignable inequívocamente al siglo XVI, reduce considerablemente las probabilidades de su asociación con la nao Santiago de la expedición de Magallanes, tal como era asumido por dichos pobladores.

Tal como señalamos anteriormente, al procurar determinar la adscripción cultural de las embarcaciones, la información obtenida a partir de las identificaciones taxonómicas de las maderas debe ser tomada con ciertos recaudos (nos referimos a los casos en los que no se cuenta 
con otra evidencia más que los restos estructurales del barco). Esto se debe a que el origen geográfico de los taxones no necesariamente corresponde con el lugar en donde fue construida la embarcación. También deben tenerse en cuenta otras cuestiones vinculadas con su historia de vida, ya que al momento del naufragio -y por muy diversos motivos- un barco puede haber pertenecido a un contexto cultural diferente al de su construcción.

Otroaspectovinculadoconlasidentificaciones taxonómicas de las maderas analizadas es que permiten evaluar cuestiones de índole tecnológica. En este sentido, se pudo observar que en su mayor parte el uso de determinadas maderas para elementos específicos de la embarcación parece ser consistente con lo indicado en fuentes referidas a la construcción naval del siglo XIX y principios del XX (por ejemplo, American Lloyd's Register of American and Foreign Shipping, 1859-1883; Desmond, [1919] 1984; Russel, 2005). Ejemplos de ello es la mención del uso de roble para elementos estructurales como la quilla o sobrequilla, abeto para forro exterior, pino para forro exterior y piezas de arboladura, y haya para cabillas. Por otra parte, el uso de abedul y pino para cuadernas parece haber sido menos habitual.

La identificación de un mayor número de muestras de madera, combinado con otras líneas de evidencia, contribuirá a comprender la asociación de elementos estructurales dispersos con determinados eventos de naufragio, así como a clarificar las cuestiones anteriormente referidas, tales como la adscripción cultural de las embarcaciones y ciertos aspectos tecnológicos.

En este punto cabe referirse a los hallazgos aislados y su posible asociación con los conjuntos identificados. Al respecto, puede señalarse que las características tipológicas de HA1 (cadena y escobén) son consistentes con aquellas observadas en el conjunto ML4, asociación que se ve reforzada por su proximidad. En cuanto a HA2, si bien sus características parecen ser coherentes con el resto de los materiales analizados, debido a la distancia que lo separa del conjunto más próximo (19 km), es necesario profundizar en su análisis así como en la dinámica costera antes de asumir algún tipo de asociación.

Finalmente, para calcular cuál es el número mínimo de naufragios presentes en el PNML, se tuvieron en cuenta aquellos elementos que casi siempre estaban representados por un único ejemplar en una embarcación. En este sentido, el hallazgo de dos molinetes para maniobra de anclas -que incluso presentan ciertas diferencias tipológicas entre sí- evidencia al menos dos naufragios. Estas piezas se encuentran respectivamente en ML1-2 y ML4, lo cual podría estar sugiriendo que cada uno de estos conjuntos representa al menos un evento de naufragio diferente. Asimismo, las similitudes o diferencias observadas en ciertos aspectos tecnológicos de las piezas relevadas permiten evaluar otras relaciones entre los materiales. En relación a este punto, la presencia de curvas metálicas en ML4 y curvas de madera en ML1-2 apoyaría la interpretación de diferentes eventos de naufragio para cada uno de esto conjuntos. Por otro lado, en ML1-2, la coexistencia de distintos tipos de recubrimiento metálico (latón y zinc) y, como ya se ha señalado, de diversos taxones de madera para un mismo tipo de elemento estructural podría estar indicando que en este conjunto habría más de un naufragio representado. Tal como se indicó más arriba, el análisis de un número mayor de muestras posibilitará analizar más cabalmente esta cuestión. A fin de ajustar la interpretación del número mínimo, en futuras etapas de trabajo se podrá realizar un análisis más detallado de aspectos como dimensiones de las piezas, materiales, sistemas de ensamblaje y unión, entre otros.

Enfunción de todolo señaladoanteriormente, de acuerdo a los análisis e interpretaciones realizados, el material de origen náutico relevado provendría de al menos dos embarcaciones de madera construidas probablemente durante el siglo XIX en el hemisferio norte. Se trataría de embarcaciones propulsadas a vela, de tamaño mediano (alrededor de 400 toneladas de arqueo). Esta información puede ser contrastada con los datos disponibles hasta el momento sobre las embarcaciones históricas naufragadas en la región presentada en la Tabla 1. Teniendo en cuenta la fecha del naufragio, su proximidad al área del PNML y el tamaño de la embarcación, los candidatos con más posibilidades son la barca estadounidense Mary E. Parker (naufragada en 1874) y la barca noruega Cuba (naufragada en 1878). La obtención de información documental referente a las características de estas embarcaciones, los 
materiales utilizados y el lugar en el que fueron construidas permitirá contrastar estas hipótesis. Desde ya, también existe la posibilidad de que se trate de naufragios no documentados. En cualquier caso, para evaluar adecuadamente estas asociaciones se requerirá avanzar en las investigaciones del registro arqueológico así como ampliar la información de fuentes documentales.

\section{CONSIDERACIONES FINALES}

La investigación interdisciplinaria que se ha llevado a cabo hasta la fecha provee contribuciones relevantes para la historia marítima del PNML. Los materiales arqueológicos de origen náutico identificados constituyen testimonios singulares de las actividades desarrollas a lo largo del tiempo en la región.

Como uno de los resultados del presente estudio, podemos señalar que no se halló evidencia material de la embarcación de la expedición de Magallanes en el área investigada del PNML. Existe la posibilidad de que los restos se encuentren fuera de los límites del Parque -ya sea hacia el norte, el sur o en el sector submareal-, o bien de que no haya sobrevivido resto alguno. Tampoco puede descartarse la posibilidad de que se haya preservado algún resto de esta embarcación en algunos de los escasos sectores costeros del Parque que no pudieron ser relevados por las razones oportunamente indicadas.

Se ha observado que en el PNML la alta energía del ambiente costero ha influido considerablemente en la preservación y distribución de los materiales. Probablemente en menor medida, la actividad antrópica -vinculada con la recuperación y reutilización de materialestambién jugó un rol relevante en estas cuestiones. La recuperación de restos náufragos ha constituido una conducta recurrente en las sociedades del pasado, por lo que la influencia de esta actividad no debe ser menospreciada al estudiar el registro arqueológico observado en el presente. En cualquier caso, es fundamental estudiar cabalmente estos procesos para comprender de qué modo han dado forma al registro arqueológico observado.

Es relevante señalar que el Parque presenta un importante potencial para el desarrollo de modelos predictivos sobre los procesos de formación de sitios de naufragio, dado que este tipo de ambientes costeros de alta energía son también característicos de otras regiones del litoral patagónico.

En lo que respecta a los restos relevados en el PNML, si bien podría postularse una posible asociación con dos de los naufragios registrados históricamente, tal como se ha indicado, se requiere recopilar más información documental sobre las características constructivas y otros datos pertinentes acerca de las embarcaciones referidas. Asimismo, un relevamiento más detallado de las piezas estructurales halladas, así como el estudio de los procesos de formación intervinientes y la caracterización de un número más representativo de muestras de elementos metálicos y de maderas de componentes estructurales contribuirían a esclarecer este aspecto.

Dado que los mencionados factores naturales implican importantes riesgos de alteración para los materiales, se propuso un plan de monitoreo. Con este fin se seleccionaron casos representativos de diferentes tipos de emplazamiento en función de su vulnerabilidad a la acción de procesos naturales. Con ello se busca detectar posibles desplazamientos de los materiales y modificaciones en su estado de preservación originados por causas naturales.

Por último, cabe destacar que los restos relevados constituyen un recurso cultural de características singulares que debe ser preservado y puesto en valor ya que representa un período trascendente de la navegación comercial: la última etapa de los grandes veleros de madera.

\section{AGRADECIMIENTOS}

Los autores desean agradecer al equipo y colaboradores del Programa de Arqueología Subacuática del Instituto Nacional de Antropología y Pensamiento Latinoamericano que participaron en el trabajo de campo y de laboratorio: Ricardo Bastida, Chris Underwood, Horacio De Rosa, Nicolás Ciarlo, Nahuel Vicchi, Mariano Lovardo y Víctor Katz. También a los Sres. Mario Hernández, Vitocho López, Jorge Segovia, Edgar Peralta, Roberto Lemaire, así como al personal de la Administración de Parques Nacionales, quienes proveyeron invalorable ayuda en el campo. Finalmente, a los evaluadores de este trabajo por sus valiosos comentarios. 


\section{FUENTES DE CONSULTA}

AGI (Archivo General de Indias), Sevilla, nd, sección Patronato 34, R.10, Relación de lo que tiene la nao Santiago.

\section{BIBLIOGRAFÍA}

Albo, F. [1522] (1946). Diario o Derrotero del viaje de Magallanes, desde el cabo de San Agustín, en el Brasil, hasta el regreso a España de la nao 'Victoria', escrito por Francisco Albo. En M. Fernández de Navarrete, Colección de los Viajes y Descubrimientos que hicieron por mar los españoles desde fines del siglo XV, Tomo IV (pp. 191-225). Buenos Aires: Editorial Guaranía.

Aldazabal, V. (2000). Primeros pasos españoles en las costas patagónicas: la expedición Magallanes y el naufragio de la 'Santiago'. Anuario de la Universidad Internacional SEK, 6, 53-61.

American Lloyd's Register of American and Foreign Shipping (varios años), New York. Recuperado de http://library. mysticseaport.org/initiative/ShipRegisterList.cfm

Argüeso, A. (2001). Asesoramiento técnico en la localidad de Puerto Santa Cruz - Proyecto Nao Santiago (Provincia de Santa Cruz). Informe preliminar. Instituto Nacional de Antropología, Buenos Aires (manuscrito).

Bastida, R., Elkin, D., Grosso, M., Trassens, M., \& Martin, J. P. (2004). The Sloop of War HMS Swift (1770): A Case Study of the Effects of Biodeterioration on the Underwater Cultural Heritage of Patagonia. Corrosion Reviews, Speciel Issue: Biodeterioration of Cultural Heritage, 22, 417-440.

Bingeman, J., Bethell, J., Goodwin, P., \& Mack, A. (2000). Copper and other sheathing in the Royal Navy. International Journal of Nautical Archaeology, 29, 218-229.

Castro, M. A. (2007). Análisis botánico (madera). En D. Elkin, C. Murray \& M. Grosso, Estudio arqueológico marítimo en el Parque Nacional Monte León: Informe Final, Anexo 8, pp. 142-167. Informe presentado a la Administración de Parques Nacionales. Instituto Nacional de Antropología, Buenos Aires: (manuscrito).

Codignotto, J., \& Ercolano, B. (2006). Estudio de la línea de base para la descripción geológica-geomorfológica y de la dinámica costera del futuro Parque Nacional Monte León. Administración de Parques Nacionales, Buenos Aires (manuscrito).

Crothers, W. L. (1997). The American-Built Clipper Ship (1850-1856): Characteristics, Construction, Details.
Camden, Maine: International Marine.

Delgado, J. P. (1986). Documentation and Identification of the Two-Masterd Schooner Neptune. Historical Archaeology, 20, 95-108

Delgado, J. P. (1997). Beached shipwreck sites. En J. P. Delgado (Ed.), Encyclopaedia of Undewater and Maritime Archaeology (pp. 57-58). Londres: Bristish Museum Press.

De Rosa, H. (2007). Análisis metalúrgicos. En D. Elkin, C. Murray \& M. Grosso, Estudio arqueológico marítimo en el Parque Nacional Monte León. Informe Final, Anexo 8, pp. 135-141. Informe presentado a la Administración de Parques Nacionales. Instituto Nacional de Antropología, Buenos Aires: (manuscrito).

Desmond, C. [1919] (1984). Wooden Ship-building. New York: Vestal.

Dumas, F. (1972). Ancient Wrecks. En A.A.V.V., Underwater Archaeology: A Nascent Discipline (pp. 27-34). Paris: UNESCO.

Elcano, J. S. de [1522] (2003). Carta de Juan Sebastián de Elcano al Emperador dándole breve relación de su viaje en la armada de Magallanes y de su regreso en la nao 'Victoria'. 6 de septiembre de 1522. En La Primera Vuelta al Mundo (pp. 9-12). Madrid: Miraguano Ediciones.

English Heritage (2004). Dendrochronology: Guidelines on producing and interpreting dendrochronological dates. London: English Heritage.

Elkin, D., Murray, C., \& Grosso, M. (2007). Estudio arqueológico marítimo en el Parque Nacional Monte León. Informe Final. Presentado a la Administración de Parques Nacionales. Instituto Nacional de Antropología, Buenos Aires, (manuscrito).

Fernández de Navarrete, M. [1837] (1946). Colección de los Viajes y Descubrimientos que hicieron por mar los españoles desde fines del siglo XV, Tomo IV. Buenos Aires: Editorial Guaranía

Galdeano, M. (2006). Enciclopedia de los barcos hundidos. Atlántico Sur \& Pacífico Sur, desde el Golfo San Jorge hasta el Golfo de Penas. Ushuaia: Zagier \& Urruty.

Gibbs, M. (2006). Cultural Site Formation Processes in Maritime Archaeology: Disaster Response, Salvage and Muckelroy 30 Years on. The International Journal of Nautical Archaeology, 35, 4-19

Godoy, J. C. (1963). Evaluación de los Recursos Naturales de la Argentina. Tomo VIII, Fauna Silvestre, Vol. 1 y 2. Buenos Aires: Consejo Federal de Inversiones.

Gregory, D. (1998). Re-burial of timbers in the marine 
environment as a means of their long term storage: experimental studies in Lynæes Sands, Denmark. The International Journal of Nautical Archaeology, 27, 343-358.

Greguss, P. (1955). Identification of living gymnosperms on the basis of xylotomy. Budapest: Akademia Kiado.

Grosso, M. (2008). Arqueología de naufragios: estudio de procesos de formación naturales en el sitio HMS Swift (Puerto Deseado, Santa Cruz). En Tesis de Licenciatura del Departamento de Ciencias Antropológicas II. Buenos Aires: Facultad de Filosofía y Letras, Universidad de Buenos Aires.

Grosso, M., Trassens, M., Murray, C., \& Bastida, R. (2013). El intermareal: un entorno complejo en la formación de sitios arqueológicos. En Actas del segundo encuentro regional de patrimonio marítimo y costero. Rosario: Facultad de Humanidades y Artes, Universidad Nacional de Rosario (en prensa).

Lenzi, J. H. (1980). Historia de Santa Cruz. Rio Gallegos: Editor A. R. Segovia.

Lloyd's Register of British and Foreing Shipping (varios años), Londres. Recuperado de http://www.maritimearchives. co.uk/lloyds-register.html

Mafra, G. de [1522?] (2003). Relación de Ginés de Mafra. En La Primera Vuelta al Mundo (pp. 139-84). Madrid: Miraguano Ediciones.

McCarthy, M. (1985). The iron hull: a brief history of iron shipbuilding. En Iron ships and steam shipwrecks: papers from the First Australian Seminar on the Management of Iron Vessels and Steam Shipwrecks (pp. 219-223). Fremantle: Western Australia Maritime Museum.

McCarthy, M. (2005). Ships' Fastenings from Sewn Boats to Steamship. College Station, Texas: Texas A\&M University Press.

McKee, E. (1976). Identification of timbers from old ships of north-western European origin. The International Journal of Nautical Archaeology, 5, 3-12.

Moreno, J. C. (1947). La isla de los leones marinos. Revista Geográfica Americana, 28(170), 193-198.

Muckelroy, K. (1978). Maritime archaeology. Londres: Cambridge University Press.

Murray, C., Elkin, D. \& Grosso, M. (2012). Relevamiento de restos de naufragios. Informe de la $2^{\circ}$ etapa del trabajo de campo (Marzo 2012). Relevamiento Histórico-arqueológico de la Costa Atlántica de Tierra del Fuego, Programa Arqueológico Costa Atlántica (Museo del Fin del Mundo, Ushuaia). Instituto Nacional de Antropología, Buenos Aires (manuscrito).
Newsom, L. A., \& Miller, R. B. (2009). Wood species analysis of ship timbers and wooden items recovered from shipwreck 31CR314, Queen Anne's Revenge site. Queen Anne's Revenge Shipwreck Project, Research Report and Bulletin Series QAR-R-09-01. Underwater Archaeology Branch, Office of State Archaeology, Department of Cultural Resources, Carolina del Norte (manuscrito).

Parodi, L. R. (1972). Enciclopedia argentina de Agricultura y Jardinería, Vol. 1, Descripción de plantas cultivadas. Buenos Aires: ACME.

Pearson, C. (Ed.) (1987). Conservation of Marine Archaeological Objects. Londres: Butterworths.

Philips, E. W. (1941). The identification of coniferous woods by their microscopic structure. The Journal of the Linnean Society of London, Bot., 52, 259-320.

Pigafetta, A. [1522?] (1954). Primer viaje en torno al globo (pp. 34-139). Colección Austral. México D. F.: EspasaCalpe.

Punta, G. (1996). Estado de situación del recurso guanero en la República Argentina - Informe Técnico Nº 6. Plan de Manejo Integrado de la Zona Costera Patagónica. Puerto Madryn: Fundación Patagonia Natural.

Record, S. J. \& Hess, R. W. (1943). Timbers of the New World. New Haven: Yale University Press.

Russell, M. (1995). Archaeology of Beached Shipwrecks: Investigations of Two Channel Islands National Park Shipwreck Scatters. En P. Forsythe Johnston (Ed.), Underwater Archaeology Procedeengs from the Socitey for Historical Archaeology Conference (pp. 147-153). Washington D.C.: Society for Historical Archaeology.

Russell, M. (2004). Beached Shipwrecks from Channel Islands National Park, California. Journal of Field Archaeology, 29, 369-384.

Russell, M. (2005). Beached Shipwreck Archaeology. Case Studies from Channel Islands National Park. Submerged Resources Center, National Park Service. Santa Fe, New México.

Smith, R. C. (1993). Vanguard of Empire: Ships of exploration in the age of Columbus. Oxford: Oxford University Press.

Solari, M. E. (1992). Anthracologie et ethnoarchéologie dans laarchipel du cap Horn (Chili). Bull. Soc. bot. Fr., Actual. bot., 139, 407-419.

Staniforth, M. (1985). The Introduction and Use of Copper Sheathing: A history. The Bulletin of the Australian Institute for Maritime Archaeology, 9, 21-48.

Steffy, J. R. (1994). Wooden Shipbuilding and the 
Interpretation of Shipwrecks. College Station: Texas A \& M University Press.

Stone, D. L. (1993). The Wreck Diver's Guide to Sailing Ship Artifacts of the 19th Century. Vancouver: Archaeological Society of British Columbia.

Transilvano, M. [1523] (1946). Relación escrita por Maximiliano Transilvano de cómo y por qué y en qué tiempo fueron descubiertas y halladas las Islas Molucas. En Colección de los Viajes y Descubrimientos que hicieron por mar los españoles desde fines del siglo XV, M. Fernández de Navarrete, Tomo IV (pp. 227-259). Buenos Aires: Editorial Guaranía.

Tubbs, C. H., \& Huston, D. R. (1990). Fagus grandiflora Ehrh., American Beech, Fagaceae, Beech family. En R. M. Burns \& B. H. Honkala (coordinadores técnicos),
Silvics of North America Volume 2. Hardwood (pp. 325-332). USDA. Forest Service, Agriculture Handbook 654. Washington D. C.: U.S. Government Printing Office.

USDA (1965). World Pinaceae. U. S. Government Printing Office (1965-O 764-741), Washington D. C.

Vázquez, M., Zangrando, A. F., Tessone, A., \& Ceraso, A. (2011). Arqueología de la costa meridional de Península Mitre. En A. F. Zangrando, M. Vázquez \& A. Tessone (compiladores), Los cazadores-recolectores del extremo oriental fueguino: Arqueología de Península Mitre e Isla de los Estado. Buenos Aires: Sociedad Argentina de Antropología.

Ward I., Larcombre, P., \& Veth, P. (1999). A New Processbased Model for Wreck Site Formation. Journal of Archaeological Science, 26, 561-570. 